Federal Reserve Bank of Dallas

Globalization and Monetary Policy Institute

Working Paper No. 93

http://www.dallasfed.org/assets/documents/institute/wpapers/2011/0093.pdf

\title{
How Much Asymmetry Is There in Bond Returns and Exchange Rates?*
}

\author{
Ippei Fujiwara \\ Bank of Japan \\ Lena Mareen Körber \\ London School of Economics \\ Daisuke Nagakura \\ Keio University
}

September 2011

\begin{abstract}
We measure asymmetries in the distribution of bond returns and exchange rates and test their statistical significance. Asymmetries are sizable when measured by the coefficient of skewness, a measure that is highly affected by outliers. In contrast, robustly measured asymmetries to outliers often disagree in sign or size, implying that much of the asymmetries measured by the coefficient of skewness can be attributed to extreme observations. Asymmetries in many government bonds returns are only statistically significant according to tests based on the coefficient of skewness. On the contrary, only tests based on robust measures indicate statistically significant asymmetries in the exchanges rates of Japanese Yen, a major funding currency for carry trades, as well as in New Zealand Dollar and Australian Dollar, major investing currencies for carry trades. This observation suggests that sources of asymmetry in carry trades and in government bond returns can be fundamentally different.
\end{abstract}

JEL codes: C12, F30, G31

\footnotetext{
* Ippei Fujiwara, Director, Financial Markets Department, Bank of Japan, 2-1-1 Nihonbashi-Hongokucho, Chuo-Ku, Tokyo 103-8660, Japan. Ippei.fujiwara@boj.or.jp. http://sites.goøgle.com/site/ippeifujiwara. Lena Mareen Körber, Department of Economics, London School of Economics and Political Science, Houghton Street, London, WC2A 2AE, UK. L.M.Koeber@lse.ac.tk. +444-020-7405-7686. Daisuke Nagakura, Department of Economics, Keio University, 2-15-45, Mita, Minatoku, Tokyo 1088345, Japan. nagakura@z7keio.jp. 81-3-3453-4511. We thank Toni Braun, Hibiki Ichiue, Karen Lewis, Masao Ogaki, Tatsuyoshi Okimoto, seminar participants at the Bank of Japan and participants of the $8^{\text {th }}$ Conference for Applied Financial Economics for their helpful comments. The views in this paper are those of the authors and do not necessarily reflect the views of the Bank of Japan, the Federal Reserve Bank of Dallas or the Federal Reserve System.
} 


\section{Introduction}

In the latter half of 2010, we observed significant fluctuations in bond yields of many developed countries. The yields gradually decreased but went up abruptly towards the end of the year. For example, the yield on a 10 year US bond remained stable from January until April at approximately 4.0\%. From the end of April to the beginning of November, the yield gradually decreased to around $2.8 \%$. In the mid of December, the yield quickly recovered to around 3.8\%. While the decrease by about 120 basis points took place over a period of six months, the increase by about 100 basis points occurred in only one month and a half. This observation suggests that the probability of a sudden and massive increase in government bond yields is higher than the probability of a decrease of the same magnitude, or that ups and downs in government bond yields are asymmetric. ${ }^{1}$

Are asymmetries in government bond yields attributable to extreme events like the recent financial crisis? Or are asymmetries a stylized fact that also characterizes historical government bond yields? To answer these questions, we study asymmetries in government bond yields. Interpreting bond excess returns as returns to a carry trade over time, we find it instructive to jointly investigate asymmetries in bond excess returns and exchange rates. Finally, we study asymmetries in returns to international bond carry trades. By an international bond carry trade, we mean return from foreign bond investments denominated by funding currency. ${ }^{2}$

We compute the degree of asymmetries using both measures that are robust against extreme observations and measures that are not. Any disagreement between robust and non-robust measures can be attributed to outliers. In addition, we formally examine whether the measured asymmetries are statistically significant using symmetry tests proposed by Bai and Ng (2005), Chen and Lin (2008) and Nagakura (2011). These symmetry tests exhibit varying degrees of robustness against extreme observations. While the performance of asymmetry measures in the presence of outliers has been studied by Kim and White (2004), evidence on

\footnotetext{
${ }^{1}$ Throughout the paper, we use the terms skewness and asymmetry interchangeably.

${ }^{2}$ The terms international bond trade and international bond carry trade are used interchangeably. So are the terms domestic bond trade and domestic bond carry trade.
} 
the performance of symmetry test when an outlier occurred in the sample is lacking. Before applying the symmetry test to our data, we therefore first assess their reliability in the presence of outliers by means of a simulation study.

Regarding the degree of asymmetry, we find that asymmetry in both domestic and international government bond returns and exchange rates is often sizable when measured by the coefficient of skewness. In contrast, when measures that are robust to extreme observations like the Bowley or Pearson coefficient are used, asymmetries tend to be small. We document that much of the disagreement between robust and non-robust measures can be attributed to the presence of outliers.

The results on the statistical significance of asymmetry in both domestic and international government bond returns echo the disagreement documented for asymmetry measures: The measured asymmetry in government bond returns is often only statistically significant if a test based on the coefficient of skewness is used. Tests based on robust asymmetry measures, in contrast, indicate that the measured asymmetries are not statistically significant for most government bond returns.

Asymmetries in the exchanges rates of Japanese Yen, a major funding currency for carry trades, as well as New Zealand Dollar and Australian Dollar, major investing currencies for carry trades, on the contrary, are only statistically significant if tests based on a robust asymmetry measure are used. However, if the holding period is longer than a month, there is no statistically significant asymmetry in most exchange rates. For short holding periods, asymmetry tends to be rather business-as-usual in markets where exchange rate carry trades are prevalent. This observation suggests that sources of asymmetry in carry trades and in government bond returns can be fundamentally different.

Recall that the expectations hypothesis predicts that the yield on a long-term bond is the average of expected short rates. Differently put, excess bond returns are constant or nil under the expectations hypothesis. Since on average, ex post bond returns are considered to represent the term premium if shocks are i.i.d, the expectation hypothesis is at odds with the skewness in return distributions. In practise, most studies reject the expectations hypothesis and emphasize the importance of time-varying term premium (e.g. Campbell and Shiller, 1991, Fama and Bliss, 
1987, Backus et al., 2001, Cochrane and Piazzesi, 2005). None of these, however, discuss asymmetric movements in term premia.

To our knowledge, documenting empirical facts on asymmetries in government bonds is new to the literature. There is, however, a rich literature on asymmetries in other financial assets. Rietz (1988) argues that the equity premium advocated by Mehra and Prescott (1985) can be explained by a low frequency event like a large drop in consumption. This implies that the distribution of equity returns is negatively skewed.

Whether or not asymmetry is a stylized fact for stock market returns is controversial. Perio $(1999,2002)$ studies asymmetry in stock returns. He cannot reject symmetry for most stock market indices considered but he documents some statistically significant asymmetry in daily individual stock returns that disappears once the holding period is increased to 1 week or 1 month. Premaratne and Bera (2005), too, find evidence of asymmetry in daily individual stock returns. Kim and White (2004), in contrast, argue that negative skewness may have been accepted too readily as a stylized fact of stock market returns.

In addition to stock market returns, asymmetries in exchange rates have attracted much attention. Brunnermeier et al. (2009) find that positive excess returns to carry trades are associated with a negative coefficient of skewness of the exchange rate: Positive excess returns are considered to be a compensation for the risk of an abrupt appreciation of low interest rate currencies, or crash risk in their terminology. Jurek (2007), however, documents that the relationship between skewness and interest differentials can have the opposite sign using risk-neutral skewness implied by option data.

Like currency carry trades, bond carry trades, which we define by funding by short-term and investing in long-term yields, may be exposed to risk that can be compared to the crash risk Brunnermeier at al. (2009) identify for exchange rates. If long term yields rise unexpectedly, the value of the bonds declines and investors start to unwind their investments, thereby amplifying the increase in long term yields and the losses from bond carry trades. Albeit similar mechanisms seem to be at work, our empirical results suggest that the risk premium in carry trades 
can be fundamentally different from the term premium. Therefore, the sources of asymmetry in financial markets may not be unique.

The remainder of this paper is organized as follows. Section 2 introduces our methodology. Empirical results are presented in Section 3 and Section 4 concludes.

\section{Methodology}

\subsection{Measures of Asymmetry}

Let $\left\{X_{t}\right\}_{t=1}^{T}$ be a strictly stationary time series with stationary distribution function $F(x) .{ }^{3}$ Denote its mean and standard deviation be $\mu$ and $\sigma$, respectively. The most widely used measure for asymmetry is the "coefficient of skewness" defined as

$$
\zeta_{S}=\frac{E\left\{\left(X_{t}-\mu\right)^{3}\right\}}{E\left\{\left(X_{t}-\mu\right)^{2}\right\}^{3 / 2}} .
$$

$\zeta_{S}$ is zero for symmetrically distributed random variables. A positive value of $\zeta_{S}$ implies that the distribution of $X_{t}$ is positively skewed or skewed to the right. The opposite interpretation applies to negative values of $\zeta_{S}$. As $\zeta_{S}$ is unobservable, we estimate it by

$$
\widehat{\zeta_{S}}=\frac{T^{-1} \sum_{t=1}^{T}\left(X_{t}-\widehat{\mu}_{T}\right)^{3}}{\left[T^{-1} \sum_{t=1}^{T}\left(X_{t}-\widehat{\mu}_{T}\right)^{2}\right]^{3 / 2}},
$$

where $\widehat{\mu}_{T}$ is the sample mean.

A second measure for asymmetry we use is the "Bowley coefficient of skewness" defined as

$$
\zeta_{B}=\frac{F^{-1}(0.75)+F^{-1}(0.25)-2 F^{-1}(0.5)}{F^{-1}(0.75)-F^{-1}(0.25)},
$$

where $F^{-1}(\tau) \equiv \inf \{x: F(x)>\tau\}$ is the $\tau$ th quantile. The sign of the Bowley coefficient has the same interpretation as sign of the coefficient of skewness. Like $\zeta_{S}$, the value of $\zeta_{B}$ is zero for symmetric distributions and bounded between -1 and 1. The coefficient of skewness $\zeta_{S}$, in contrast, can take arbitrarily large values. A natural estimator for $\zeta_{B}$ is its sample analogue

$$
\widehat{\zeta}_{B}=\frac{F_{T}^{-1}(0.75)+F_{T}^{-1}(0.25)-2 F_{T}^{-1}(0.5)}{F_{T}^{-1}(0.75)-F_{T}^{-1}(0.25)},
$$

\footnotetext{
${ }^{3}$ Note that the assumption of stationarity does not exclude conditional heteroskedasticity, making our method applicable to financial data.
} 
where $F_{T}^{-1}(\tau) \equiv \inf \left\{x: F_{T}(x)>\tau\right\}$ is the $\tau$ th sample quantile, $F_{T}(x) \equiv \sum_{t=1}^{T} I\left(X_{t} \leq\right.$ $x), x \in \mathbb{R}$ is the empirical distribution function and $I(\cdot)$ is the indicator function that is 1 if $X_{t} \leq x$ and 0 otherwise.

A third measure is the "Pearson coefficient of skewness" defined as

$$
\zeta_{P}=\frac{\mu-F^{-1}(0.5)}{\sigma} .
$$

A natural estimator for $\zeta_{P}$ is

$$
\widehat{\zeta}_{P}=\frac{\bar{X}-F_{T}^{-1}(0.5)}{\widehat{\sigma}}
$$

The Pearson coefficient compares mean and median, which are equal for symmetric distributions. Like $\zeta_{B}, \zeta_{P}$ satisfies $-1 \leq \zeta_{P} \leq 1$.

The values of $\zeta_{S}$ lie in a different range when compared to the values of $\zeta_{B}$ and $\zeta_{P}$, making a direct comparison of the measured quantities difficult. To better understand how different degrees of skewness correspond to the values of these three measures, Figure 1 shows asymmetric distributions with the corresponding values of the three asymmetry measures. Observe that the same degree of skewness produces widely different values of these three measures. The values of $\zeta_{S}$ can be about $8 \sim 10$ times as large as $\zeta_{B}$ and $\zeta_{P}$. We therefore have to exercise care in the interpretation of the measured asymmetries.

Recall that we cannot directly observe the population values of the skewness measures but we have to estimate them. Kim and White (2004) conduct a simulation study to assess the performance of $\widehat{\zeta}_{S}, \widehat{\zeta}_{B}$ and $\widehat{\zeta}_{P}$ in the presence of outliers. They find that $\widehat{\zeta}_{S}$ can be severely biased if an outlier was observed in the sample. $\widehat{\zeta}_{B}$ and $\widehat{\zeta}_{P}$, in contrast, are robust against outliers, and we thus call them "robust measures" in this paper.

\subsection{Tests for Symmetry}

To assess the statistical significance of the measured asymmetries, we apply the generalized symmetry tests proposed by Chen and Lin (2008, CL) and Bai and Ng (2005). These tests are applicable to weakly dependent processes. ${ }^{4}$

\footnotetext{
${ }^{4}$ For our data at hand, we tested the i.i.d. assumption by the BDS test (Brock et al. 1996, Kanzler, 1999) and rejected the null of i.i.d. for bond returns and exchange rates with a few exceptions. The results are available upon request from the authors.
} 
Given a strictly stationary time series $\left\{X_{t}\right\}_{t=1}^{T}$, define $z_{t}=\left(X_{t}-\mu\right) / \sigma$. Observe that the distribution of $z_{t}$ is symmetric if and only if $F_{z}(z)=1-F_{z}(-z) \forall z \in$ $\mathbb{R}$, where $F_{z}(z)$ is the distribution function of $z_{t}$. Let $\phi(z)$ be a $q$-dimensional, continuously differentiable odd function. The symmetry tests of CL are based on the fact that symmetry of $z_{t}$ implies

$$
E\left\{\phi\left(z_{t}\right)\right\}=\int_{\mathbb{R}_{-}} \phi(z) \mathrm{d} F_{z}(z)+\int_{\mathbb{R}_{+}} \phi(z) \mathrm{d} F_{z}(z)=\int_{\mathbb{R}_{+}}[\phi(z)+\phi(-z)] \mathrm{d} F_{z}(z)=0
$$

The idea of CL's symmetry tests is to use the sample analogue of $E\left\{\phi\left(z_{t}\right)\right\}, T^{-1} \sum_{t=1}^{T} \phi\left(\widehat{z}_{t}\right)$, to test whether $E\left\{\phi\left(z_{t}\right)\right\}$ is significantly different from zero, where $\widehat{z}_{t}=\left(X_{t}-\widehat{\mu}_{T}\right) / \widehat{\sigma}_{T}$ and $\widehat{\sigma}_{T}^{2}$ is the sample variance.

CL use three different asymmetry measures. Their first measure is $\phi^{B N}(z)=z^{3}$, and the symmetry test based on it is equivalent to the test of Bai and $\mathrm{Ng}$ (2005). The second asymmetry measure, $\phi^{P B}(z)=\tan ^{-1}(z)$, has been proposed by Premarante and Bera (2005). Finally, $\phi^{C C K}(z)=z /\left(1+z^{2}\right)$ was introduced by Chen, Chou, and Kuan (2000) for testing time reversibility. Note that, in contrast to $\phi^{B N}, \phi^{P B}$ and $\phi^{C C K}$ are bounded functions. This property avoids the finite 6 -th moment assumption that is necessary for the test of Bai and $\mathrm{Ng}$.

CL propose two different methods to obtain asymptotically pivotal test statistics. One is based on the HAC method, and the other uses KVB-KL method (Kiefer, Vogelsang, and Bunzel, 2000, Kuan and Lee, 2006). Throughout, we denote CL's tests with $\phi^{B N}(z), \phi^{P B}(z)$, and $\phi^{C C K}$ by $\mathrm{H}(\mathrm{BN}), \mathrm{H}(\mathrm{PB}), \mathrm{H}(\mathrm{CCK}), \mathrm{K}(\mathrm{BN}), \mathrm{K}(\mathrm{PB})$, and $\mathrm{K}(\mathrm{CCK}) \mathrm{H}($.$) and \mathrm{K}($.$) stand for the HAC and KVB-KL method, respectively.$

A modification of the CL tests is proposed in Nagakura (2011). Instead by mean and standard deviation, Nagakura (2011) standardizes $\left\{X_{t}\right\}_{t=1}^{T}$ by median (0.5th quantile) and interquartile range (0.75th quantile minus 0.25 th quantile). This modification avoids the assumption of finite moments of any order. We will denote Nagakura's (2011) modification of CL's tests based on $\phi^{P B}$ by $\mathrm{HQ}(\mathrm{PB})$ and $\mathrm{KQ}(\mathrm{PB})$, where $\mathrm{HQ}($.$) refers to the HAC method and \mathrm{KQ}($.$) to the KVB-KL$ method, and Q stands for quantile. ${ }^{5}$

CL carry out a simulation study to assess the finite sample properties of their

\footnotetext{
${ }^{5}$ Nagakura (2011) finds that his modification only works well for $\phi^{P B}$.
} 
tests. They find that the empirical sizes of $\mathrm{K}$ and $\mathrm{H}$-tests are reasonably close to the nominal level for $\phi^{C C K}$ and $\phi^{P B}$, whereas tests with $\phi^{B N}$ are properly sized only when the simulated data is not generated from heavy tailed distributions. In addition, their tests posses high power against various weakly dependent processes.

In the remainder of this section, we report results of a complementary simulation study. The data generating process is the GARCH model

$$
x_{t}=\beta x_{t-1}+u_{t}, \quad u_{t}=\epsilon_{t} h_{t}^{1 / 2}, \quad h_{t}=\alpha_{0}+\alpha_{1} h_{t-1}+\alpha_{2} u_{t-1}^{2}
$$

The parameters of $(8)$ are set to $\left(\beta, \alpha_{0}, \alpha_{1}, \alpha_{2}\right)=(0.05,0.1,0.9,0.05)$ as in CL. The sample size is 100 and the number of replications is 500. To obtain the empirical sizes and powers, we consider different symmetric and asymmetric distributions for $\epsilon_{t}$ including the normal distribution, the student-t distribution, the lognormal distribution, the exponential distribution and distributions generated by the generalized $\lambda$-distributions. All asymmetric distributions considered exhibit positive skewness. The specific parametrization of these distributions is provided in the Appendix.

Our simulation study complements the finite sample results provided by CL. Table 1 contains empirical powers and sizes of the tests proposed by CL and Nagakura(2011) for a sample size of 100, a sample size that occurs in our empirical analysis below. CL, in contrast, only report results for sample sizes of 500 and larger. We find that all tests are correctly sized even in small samples, with exception of $\mathrm{K}(\mathrm{BN})$, which is oversized. The tests by CL have good powers against most alternatives.

As we will document in section 3, there are outliers in the time series of government bond returns and exchange rates. Evidence on the performance of asymmetry measures in such circumstances has been provided by Kim and White (2004). However, we not only measure, but also test whether the measured asymmetries are statistically significant. Before applying the tests introduced above to empirical data, we conduct a simulation study to assess their reliability in the presence of outliers. Outliers are constructed as in Kim and White (2004). To construct a negative outlier, they propose to calculate the ratio between an outlier and the 25th quantile in a representative data set. Let this ratio be $m$ and let $\tau$ be the location 
of the outlier in the representative data set. In the simulated data, the observation at $\tau$ is replaced with the 25 th quantile of the simulated data multiplied by $m$. A positive outlier is constructed analogously with the 25th quantile replaced by the 75th quantile. We use 10 year bonds as a representative data set. The maximum $m$ is observed for Japanese bonds with a holding period of 1 month and equals $26.55 .^{6}$

Table 2 reports finite sample properties of $\mathrm{H}($.$) and \mathrm{K}($.$) in the presence of a$ positive outlier. We find that $\mathrm{HQ}(\mathrm{PB}), \mathrm{K}(\mathrm{CCK})$ and $\mathrm{KQ}(\mathrm{PB})$ are the only tests with correct sizes. $\mathrm{K}(\mathrm{PB})$ has proper sizes for some distributions. Observe in particular that none of the $\mathrm{H}($.$) tests has correct sizes. Regarding powers, the \mathrm{H}($.$) tests as$ well as $\mathrm{K}(\mathrm{BN})$ have low powers against most alternatives, $\mathrm{HQ}(\mathrm{PB}), \mathrm{K}(\mathrm{CCK})$ and $\mathrm{K}(\mathrm{PB})$ and $\mathrm{K}(\mathrm{CCK})$ have high powers and $\mathrm{KQ}(\mathrm{PB})$ has moderate powers.

The corresponding results for a negative outlier are provided in Table 3. While the results for sizes are qualitatively identical to the situation of a positive outlier, powers are significantly different. Recall that the asymmetric distributions considered have a positive skew. We find that against some alternatives, the powers of the $\mathrm{H}($.$) and \mathrm{K}($.$) tests developed by CL are zero. The tests proposed by Nagakura$ (2011), in contrast, can detect asymmetry in these situations.

Given the severe size distortions of some of these tests in the presence of outliers, we only use tests based on the KVB-KL approach as well as HQ(PB) in the empirical sections.

\section{Empirical Analysis}

\subsection{Domestic Bond Returns}

To compute holding period excess returns, we use zero coupon yields for Japan, the U.S., Germany, and Canada for the period from 1997 to 2007. Except for Japan, daily zero coupon yields are publicly available at the web site of each Central Bank. ${ }^{7}$ For Japan, we use the zero coupon yields reported in Ichiue and Ueno (2006).

\footnotetext{
${ }^{6}$ For comparison, the $m$ calculated by Kim and White for the daily S\&P index is 48.62 .

${ }^{7}$ For the U.S., http://www.federalreserve.gov/pubs/2006.

For Germany, http://www.bundesbank.de/statistik/statistik_zinsen.en.php.

For the U.K., http://bankofengland.co.uk/statistics/yieldcurve/archive.htm.

For Canada, http://www.bankof canada.ca/en/rates/yield_curve.html.
} 
However, the reported maturity in these web sites is quarterly or longer. To calculate daily, weekly and monthly returns, we apply the Svensson (1994) model:

$$
\begin{aligned}
y^{n}= & \beta_{0}+\beta_{1} \frac{\tau_{1}-\tau_{1} \exp \left(-\frac{n}{\tau_{1}}\right)}{n} \\
& +\beta_{2}\left[\frac{\tau_{1}-\tau_{1} \exp \left(-\frac{n}{\tau_{1}}\right)}{n}-\exp \left(-\frac{n}{\tau_{1}}\right)\right]+\beta_{3}\left[\frac{\tau_{2}}{n}-\exp \left(-\frac{n}{\tau_{2}}\right)\left(1+\frac{\tau_{2}}{n}\right)\right],
\end{aligned}
$$

where $n$ is the maturity and $y(n)$ is the yield at maturity $n$. The time dependency of the parameters $\beta_{i}$ and $\tau_{i}$ is suppressed. We estimate the unknown parameters of the model with the data on zero coupon yields with exception of the U.S., we use the parameter estimates reported on their web site. Using the model in equation (9) with estimated parameters, we can compute the zero coupon yields as well as bond prices at any maturity $n$.

For the risk free rate, we use the 1 month LIBOR rates for monthly holding periods and the policy interest rates for daily and weekly holding periods since LIBOR is very volatile if the holding period is short. Let $i_{t}$ denote the risk free rate. The risk free rate and the yields are expressed in annualized terms. We define the yield spread of a $n$-bond in period $t, y s_{t}^{(n)}$, as

$$
y s_{t}^{(n)}=y_{t}^{(n)}-i_{t}
$$

Bond prices, $b_{t}^{(n)}$, are calculated as

$$
b_{t}^{(n)}=\exp \left\{-n y_{t}^{(n)}\right\}
$$

The ex-post excess return of holding a bond for one period, $x_{t+1}^{(n)}$, is defined as

$$
x_{t+1}^{(n)}=E_{t}\left\{\log \left(\frac{b_{t+1}^{(n-1)}}{b_{t}^{(n)}}\right)-i_{t}\right\},
$$

where $\log \left(b_{t+1}^{(n-1)} / b_{t}^{(n)}\right)$ is expressed in annualized terms by dividing it by the length of holding period as a fraction of one year.

Tables 4, 5 and 6 report descriptive statistics for bond excess returns. Consider first the mean yield spreads and the mean excess returns reported in columns 2 
and 4. Observe that these variables exhibit a similar pattern. This observation is probably not surprising as we can express excess returns as

$$
\log \left(\frac{b_{(t+1)}^{(\tau-1)}}{b_{t}^{(\tau)}}\right)-i_{t}=y_{t}^{(\tau)}-i_{t}-(\tau-1)\left(y_{t+1}^{(\tau-1)}-y_{t}^{(\tau)}\right)
$$

Equation (13) implies that small changes in yields are associated with large changes in prices if $\tau$ is large, providing a rationale for the observation that long term bond returns are more volatile as previously observed by Fama (1984).

Consider in turn the asymmetry measures reported in columns 6, 9 and 10 and illustrated graphically in Figures 2, 3 and 4. Figure 2 shows that the term structure of the coefficient of skewness is downward sloping with exception of Canadian bonds with a daily holding period and UK bonds, where it is flat. However, note that in contrast to the other countries, the term structure of interest rates was not upward sloping in UK as it can be inferred from the negative mean yield spread of UK bonds. Figures 3 and 4 document that this trend disappears for most countries if a robust skewness measure is used instead of the coefficient of skewness.

There is considerable disagreement about the sign of the asymmetry between different measures, in particular if the holding period is short. In addition, the robust measures are often small in absolute value, while the coefficient of skewness can be sizable. Consider, for example, daily returns to Japanese bonds with 5 years to maturity. We find that Bowley and Pearson coefficient are only 0.03 and 0.001 , respectively, while the coefficient of skewness equals -0.56 . Similar observations can be made for different countries, different maturities and different holding periods. As discussed above, however, differences in scale hamper a direct comparison of the different asymmetry measures. But a disagreement of this magnitude suggests that the coefficient of skewness may be biased due to extreme observations as previously reported by Kim and White (2004).

To assess the disagreement between the different asymmetry measures, Figures 5 and 6 report the time series of 1 and 10 year Japanese government bond excess returns standardized by median and interquartile range. Albeit there is rarely any contemporaneous correlation of bond returns across countries, the corresponding figures for the other countries exhibit qualitative properties that are very similar to 
those of Japanese bond returns, and are therefore omitted. Because the time series of government bond returns are highly correlated across maturities in particular for longer maturities, we only report maturities of 1 and 10 years. ${ }^{8}$ To ease interpretation, horizontal lines at 3 and -3 are added to the Figures: If the standardized series were normally distributed, the probability of obtaining a realization that exceeds 3 in absolute value is only approximately $0.0005 .^{9}$ Observe that there is a significant number of values more than three, suggesting tails that are thicker than those of the normal distribution. The number of those values decreases as the holding period becomes longer. Finally, there are clusters of those values, implying that they are correlated across time.

An alternative method to illustrate these properties of the time series of government bonds are kernel density estimates. Figure 7 reports kernel density estimates of 10 year Japanese government bonds when compared to a normal density with equal mean and standard deviation. To ease comparisons across holding periods, all returns are annualized. We find that the tails are longer when compared to the normal density, and the negative tail tends to be longer for all holding periods. However, the long left tail seems to be attributable to a few very extreme observations, mirroring the extreme, negative observation in Figure 6. Consider, for example, the distribution of bond returns with a daily holding period shown in the left figure. Here, the coefficient of skewness is -0.76 , while the Bowley and Pearson coefficient equal 0.05 and 0.005 , corroborating the findings of Kim and White (2004) that the coefficient of skewness is biased when extreme observations occur, while the robust measures are unaffected by it.

Tables 7, 8 and 9 summarize the statistical significance of the measured asymmetries in bond returns. For daily holding periods, we find that for Japan and Germany, mainly the tests based on the coefficient of skewness, $\mathrm{K}(\mathrm{BN})$, indicate that some of the measured asymmetries are statistically significant. However, as

\footnotetext{
${ }^{8}$ The results for all countries and all maturities are available upon request from the authors.

${ }^{9}$ For normally distributed random variables, the median and mean are identical and the interquartile range equals approximately 1.35 standard deviations. Let $Z_{t}$ be a random variable standardized by mean and standard deviation, and let $\tilde{Z}_{t}$ be the same random variable standardized by median and interquartile range. Then, $P\left(\left|\tilde{Z}_{t}\right|>3\right)=P\left(\left|Z_{t}\right|>1.35 \times 3\right) \approx 0.00005$.
} 
documented above, $\mathrm{K}(\mathrm{BN})$ is not properly sized. In addition, $\mathrm{K}(\mathrm{BN})$ relies on the assumption of a finite sixth moment, which may not be satisfied here. Therefore, the results of $\mathrm{K}(\mathrm{BN})$ should be interpreted with caution. For US, UK and Canada, there is significant skewness for some maturities according to Nagakura's (2011) tests $\mathrm{KQ}(\mathrm{PB})$ and $\mathrm{HQ}(\mathrm{PB})$.

When the holding period is equal to one week, also the robust tests, $\mathrm{K}(\mathrm{CCK})$, $\mathrm{K}(\mathrm{PB}), \mathrm{KQ}(\mathrm{PB})$ and $\mathrm{HQ}(\mathrm{PB})$, are significant for Japanese bonds with long maturities. For the other countries, there are some statistically significant asymmetries according to $\mathrm{K}(\mathrm{BN})$ for long maturities while the robust tests do not indicate statistically significant skewness in most cases.

Finally, for monthly holding periods, Japanese bonds returns are significantly skewed according to $\mathrm{K}(\mathrm{BN})$ and so are UK and US bond returns for some short maturities. There are no significant asymmetries in Canadian nor in German bonds.

Overall, there is more statistically significant asymmetry in government bond returns according to the test based on the coefficient of skewness, $\mathrm{K}(\mathrm{BN})$, when compared to the robust tests.

A possible caveat to comparing statistical significance across holding periods are differences in sample sizes. As the sample size declines, the test is less powerful in detecting deviations from the null hypothesis of symmetry. As documented in our simulation studies above, however, the tests still have good powers in small samples. Therefore, we expect that only a part of the differences in the significance across holding periods can be explained by differences in sample size.

\subsection{Exchange Rates}

We use the daily, weekly, monthly and quarterly data on exchange rates for Australian Dollar (AUD), Canadian Dollar (CAD), Japanese Yen (JPY), New Zealand Dollar (NZD), Swiss Franc (CHF) and Pound Sterling (GBP) relative to U.S Dollar. for the period is from 1986 to $2006 .^{10}$

Table 10 reports descriptive statistics for the first difference of the logarithm of the nominal exchange rates. The values of the Bowley and Pearson coefficients

\footnotetext{
${ }^{10} \mathrm{We}$ chose this period to make our results comparable to those of Brunnermeier et al. (2009).
} 
reported in columns 8 and 9 are only between approximately $0.01 \sim 0.08$ in absolute value except for quarterly data, where the robust measures take values up to 0.25. The values of the coefficients of skewness reported in column 4 are often more than ten times larger than the robust skewness measures. Albeit these different skewness measures are not directly comparable, we have documented above that a difference of this magnitude is unusual. In addition, for some exchange rates, there is also disagreement in sign between the robust measures and the coefficient of skewness.

Figure 8 reports time series of daily and quarterly JPY exchange rates standardized by median and interquartile range. The interpretation of these Figures is identical to the corresponding Figures 5 and 6 for bond returns, and the same observations on the frequency of outliers across holding periods and clustering apply. Figure 8 shows that the JPY exchange rate exhibits one large positive outlier, and much of the disagreement between the different asymmetry measures can be attributed to it.

The corresponding kernel density estimates are shown in Figure 9. For purposes of comparison, the density of a normal distribution with identical mean and standard deviation is added. Observe first that the coefficient of skewness is equal to $1 / 2$ for both figures. The robust measures, in contrast, are approximately equal to zero for daily exchange rates and approximately equal to 0.2 for quarterly exchange rates. This disagreement reflects the casual observation that for daily exchange rates, the asymmetry measured by the coefficient of skewness can be attributed to probably one single, extreme observation.

The results of the symmetry tests are reported in Table 11. For daily and weekly holding periods, symmetry tests based on robust measures indicate that there is significant skewness in some exchange rates, in particular in JPY, a major funding currency, as well as in NZD and AUD, major investing currencies. This result corroborates the previous findings of Brunnermeier et al. (2009) that skewness in exchange rates, or crash risk in their terminology, must be compensated by positive excess returns to carry trades. In contrast, $\mathrm{K}(\mathrm{BN})$, the test based on the coefficient of skewness, finds that the measured asymmetry is not statistically significant with exception of GBP for daily and monthly holding periods. Recall from the simulation 
study carried out in Section 3, however, that $\mathrm{K}(\mathrm{BN})$ may not be properly sized and required a finite 6 th moment.

\subsection{International Bond Returns}

Our analysis of international bond returns combines the previous sections on bond carry trades and currency carry trades. By an international bond return, we mean an investment where funds are borrowed at the short rate in one country and invested in bonds in another country. ${ }^{11}$ The sample period 1997-2007, which is identical to the sample period for domestic bond returns.

We only report returns to trades that borrow at the Japanese short rate and invest in US bonds as the Japanese short rate was one of the major funding currency for carry trades. ${ }^{12}$ Summary statistics are presented in Table 12. Domestic bond returns alike, international bond returns exhibit disagreement in sign between different asymmetry measures reported in columns 5, 8 and 9. International returns exhibit more negative skewness measured by the coefficient of skewness when compared to domestic returns. While the absolute value of the coefficient of skewness rarely exceeds 0.5 for domestic returns, it exceeds 1 for most international returns. In contrast, the robust asymmetries measured in international bond returns is similar magnitude as those in domestic returns. Taken together, the disagreement between the different measures is exaggerated in international bond returns when compared to domestic bond returns, suggesting a positive correlation between the outliers in exchange rates and US government bond returns.

To understand why, Figures 11 and 12 show the time series of international 1 and 10 year bond returns after standardizing by median and interquartile range. As domestic bonds and exchange rates, we observe a high frequency of outliers that is decreasing in the holding period, and clustering of outliers in time. We find that the series exhibits one single very negative outlier that can explain much of the disagreement between asymmetry measures.

\footnotetext{
${ }^{11}$ We have also examined the returns to hedged currency carry trades. As expected, these results are quantitatively and qualitatively very similar to the bond returns reported in the previous section.

${ }^{12} \mathrm{~A}$ complete set of results is available from the authors upon request.
} 
Figure 13 reports estimated kernel densities for 10 year international bond returns. As for domestic bond returns, the tails are longer than the tails of a normal density with equal mean and standard deviation, and the left tail is longer than the right tail, hinting at negative asymmetry, albeit the long negative tail is attributable to a few extreme observations as illustrated in Figure 12. These few extreme observations have a large effect on the coefficient of skewness, which equals -2 for the distribution of returns with a weakly holding period. The same distribution is characterized by a Bowley and Pearson coefficient of only 0.05 and -0.04 .

Test results are reported in Table 13. For daily, monthly as well as for most weekly holding periods, $\mathrm{K}(\mathrm{BN})$ indicates significant skewness for all maturities, while the tests based on robust measures of asymmetry are not significant. As for asymmetry measures, we explain this disagreement by the presence of a very negative outlier as illustrated in Figures 11 and 12.

\section{Conclusion}

This paper documents that asymmetries in exchange rates and in both domestic and international government bond returns are often sizable when measured by the coefficient of skewness. Robust measures often disagree in sign and we show that the disagreement between measures can be attributed to the presence of extreme observations. Asymmetries in government bonds are often only statistically significant according to tests based on the coefficient of skewness. On the contrary, asymmetries in Japanese Yen, a major funding currency for carry trades, and in New Zealand Dollar as well as in Australian Dollar, major investing currencies for carry trades, are only statistically significant if tests based on robust measures are used. We cannot find much statistically significant asymmetries in exchange rates if the holding period equals 1 month or longer.

These findings have implications for affine term structure models. These models assume normally, and thus symmetrically, distributed bond returns. Our findings suggest that these assumptions may not be warranted in particular if the holding period is short, questioning the reliability of results derived from these models. 
One interesting question for further research concerns explaining the conditionality in asymmetry in financial data. Brunnermeier et al. (2009) document that interest rate differentials and skewness of exchange rates are negatively associated in the cross section when asymmetry is measured by the coefficient of skewness. They argue that the high returns compensate investors for the crash risk captured by the negative coefficient of skewness. By inspection of the descriptive statistics for exchange rates (Table 10), the same relationship holds in our data regardless of the asymmetry measure used. The descriptive statistics for both domestic and international government bond returns (Tables 4, 5, 6 and 12), however, show that skewness is unrelated to return in particular if robust asymmetry measures are used, and an argument analogue to the one for exchange rates cannot explain the measured asymmetry in government bond returns. While the the negative skewness in exchange rates is conditional on a high interest differential, the skewness in bond returns may be due to a Peso problem, an unpredictable rare event, that has been studied by Barro (2009), Gourio (2009) and Burnside et al. (2011). ${ }^{13}$ This observation suggests that the risk premium in carry trades can be fundamentally different from the term premium. Further research using conditional methods is needed to address this question in a rigorous manner.

Another possible extension of this work is methodological. Albeit some of the tests used in the present paper are robust to extreme observations, they are unrelated to robust measures of asymmetry: The asymmetry measures these tests are based upon are unrelated to the robust asymmetry measures as the coefficients of Bowley and Pearson used to measure asymmetry in practise. In work in progress we therefore develop pointwise and uniform symmetry test based on quantile measures such as Bowley's coefficient (Körber, 2011).

\footnotetext{
${ }^{13}$ This finding is counter to a hypothesis put forward by Brunnermeier et al. (2009), namely, that "the high returns of negatively skewed assets could be part of a general phenomenon." (p. $324)$.
} 


\section{Appendix B: Distributions used in the simulation study}

The symmetric distributions considered are:

S1 G(0,1): A standard normal distribution

S2 t(5): A student-t distribution with 5 degrees of freedom

S3 $\mathrm{L}(0, .19754, .134915, .134915)$ : Generalized $\lambda$-distribution defined by the inverse of the cumulative distribution function $F^{-1}(x)=\lambda_{1}+\left(x^{\lambda_{3}}-(1-x)^{\lambda_{4}}\right) / \lambda_{2}$, with $\lambda_{1}=0, \lambda_{2}=0.19754, \lambda_{3}=\lambda_{4}=0.134915$

S4 L(0,-1,-.08,-.08): Generalized $\lambda$-distribution defined as in S3

S5 L(0.-1,-.24,-.24): Generalized $\lambda$-distribution defined as in S3

The asymmetric distributions considered are:

A1 $\operatorname{Logn}(0,1)$ : Lognormal distribution with mean equal to 0 and variance equal to 1

A2 $\operatorname{Exp}(1):$ Exponential distribution with mean and variance equal to 1

A3 $\mathrm{L}(0,1,1.4, .25)$ : Generalized $\lambda$-distribution defined as in S3

A4 $\mathrm{L}(0,1,3,1)$ : Generalized $\lambda$-distribution defined as in S3

A5 L(0,-1,-.0075,-.03) : Generalized $\lambda$-distribution defined as in S3

A6 $\mathrm{L}(0,-1,-.1,-.18)$ : Generalized $\lambda$-distribution defined as in S3

A7 L(0,-1,-.001, -.13) : Generalized $\lambda$-distribution defined as in S3 


\section{References}

[1] Backus, David, Silverio Foresi, Abon Mozumdar, and Liuren Wu, 2001, Predictable Changes in Yields and Forward Rates, Journal of Financial Econometrics, 59, 281-311.

[2] Bai, Jushan, and Serena Ng, 2005, Tests for Skewness, Kurtosis and Normality for Time Series Data, Journal of Business and Economic Statistics 23, 50-60.

[3] Barro, Robert 2009. "Rare Disasters, Asset Prices, and Welfare Costs", American Economic Review 99, 243-64.

[4] Brock, William, William Dechert, Jose Scheinkman, and Blake LeBaron, 1996, A Test for Independence Based on the Correlation Dimension, Econometric Reviews 15, 197-235.

[5] Brunnermeier, Markus, Stefan Nagel, and Lasse Pedersen, 2009, Carry Trades and Currency Crashes, NBER Macroeconomics Annual 2008, 313-347.

[6] Burnside, Craig, Martin Eichenbaum, Isaac Kleshchelski and Sergio Rebelo, 2011, Do Peso Problems Explain the Returns to the Carry Trade?, Review of Financial Studies 24, 853-891.

[7] Campbell, John, and Robert Shiller, 1995, Yield Spreads and Interest Rate Movements: A Bird's Eye View, Review of Economic Studies, 58, 495-514.

[8] Chen, Yi-Ting, Ray Chou, and Chung-Ming Kuan, 2000, Testing Time Reversibility without Moment Restrictions, Journal of Econometrics 95, 199-218.

[9] Chen, Yi-Ting, and Chang-Ching Lin, 2008, On the Robustness of Symmetry Tests for Stock Returns, Studies in Nonlinear Dynamics and Econometrics 12, $1-37$.

[10] Cochrane, John and Monika Piazzesi, 2005. "Bond Risk Premia," American Economic Review 95, 138-160. 
[11] Fama, Eugene, 1984, Term Premiums and Bond Rerturns, Journal of Financial economics $13,529-546$.

[12] Fama, Eugene and Robert Bliss, 1987, "The Information in Long-Maturity Forward Rates" American Economic Review 77, 680-92.

[13] Gourio, Francois, 2009, "Disasters Risk and Business Cycles," NBER Working Paper 15399,

[14] Ichiue, Hibiki, and Yoichi Ueno, 2006, Monetary Policy and the Yield Curve at Zero Interest: The Macro-Finance Model of Interest Rates as Options, Bank of Japan Working Paper Series 06-E-16.

[15] Jurek, Jakub (2007), "Crash-Neutral Currency Carry Trades", SSRN working paper

[16] Kanzler, Ludwig 1999, Very Fast and Correctly Sized Estimation of the BDS Statistic, DPhil Thesis, University of Oxford.

[17] Kendall, Maurice, and Alan Stuart, 1969, The Advanced Theory of Statistics, McGraw Hill.

[18] Kiefer, Nicholas, Timothy Vogelsang, and Helle Bunzel, 2000, Simple Robust Testing of Regression Hypotheses, Econometrica 68, 695-714.

[19] Kim, Tae-Hwan, and Halbert White, 2004, On more Robust Estimation of Skewness and Kurtosis, Finance Research Letters 1, 56-73.

[20] Körber, Lena, 2011, "Robust Symmetry Tests for Time Series Data", mimeo.

[21] Kuan, Chung-Ming, and Wei-Ming Lee, 2006, Robust M Tests without Consistent Estimation of Asymptotic Covariance Matrix, Journal of the American Statistical Association 101, 1264-1275.

[22] Mehra, Rajnish and Edward Prescot, 1985, "The Equity Premium: A Puzzle", Journal of Monetary Economics 15, 145-161. 
[23] Nagakura, Daisuke, 2011, “Testing for Symmetry of Distribution”, SSRN working paper, http://ssrn.com/abstract=1906332

[24] Peiro, Amado, 1999, Skewness in Financial Returns, Journal of Banking and Finance 23, 847-862.

[25] Peiro, Amado, 2002, Skewness in Individual Stocks at Different Investment Horizons, Quantitative Finance 2, 139-146.

[26] Premaratne, Gamini, and Anil Bera, 2005, A Test for Symmetry with Leptokurtic Financial Data, Journal of Financial Econometrics 3, 169-187.

[27] Rietz, Thomas, 1988, "The Equity Premium A Solution", Journal of Monetary Economics 22, 117-131.

[28] Svensson, Lars, 1994, Estimating and Interpreting Forward Rates: Sweden 1992-4, NBER Working Paper 4871. 
Table 1: Simulation results without outlier

(a) Empirical Sizes

\begin{tabular}{lllllllll}
\hline & $\mathrm{H}(\mathrm{BN})$ & $\mathrm{H}(\mathrm{CCK})$ & $\mathrm{H}(\mathrm{PB})$ & $\mathrm{HQ}(\mathrm{PB})$ & $\mathrm{K}(\mathrm{BN})$ & $\mathrm{K}(\mathrm{CCK})$ & $\mathrm{K}(\mathrm{PB})$ & $\mathrm{KQ}(\mathrm{PB})$ \\
\hline $\mathrm{G}(0,1)$ & 6.00 & 6.00 & 6.20 & 3.80 & 7.00 & 5.60 & 5.80 & 2.20 \\
$\mathrm{t}(5)$ & 3.20 & 5.60 & 5.40 & 3.00 & 11.00 & 4.20 & 5.20 & 2.80 \\
$\mathrm{~L}(0, .19754, .134915, .134915)$ & 4.60 & 4.80 & 4.00 & 3.60 & 4.80 & 3.20 & 3.60 & 3.00 \\
$\mathrm{~L}(0,-1,-.08,-.08)$ & 3.20 & 6.20 & 5.60 & 3.80 & 11.00 & 4.60 & 5.80 & 4.00 \\
$\mathrm{~L}(0 .-1,-.24,-.24)$ & 3.20 & 5.80 & 5.20 & 2.60 & 14.20 & 7.60 & 7.60 & 2.20 \\
\hline
\end{tabular}

(b) Empirical Powers

\begin{tabular}{lllllllll}
\hline & $\mathrm{H}(\mathrm{BN})$ & $\mathrm{H}(\mathrm{CCK})$ & $\mathrm{H}(\mathrm{PB})$ & $\mathrm{HQ}(\mathrm{PB})$ & $\mathrm{K}(\mathrm{BN})$ & $\mathrm{K}(\mathrm{CCK})$ & $\mathrm{K}(\mathrm{PB})$ & $\mathrm{KQ}(\mathrm{PB})$ \\
\hline $\operatorname{Logn}(0,1)$ & 42.00 & 90.00 & 75.80 & 96.60 & 15.80 & 92.00 & 96.20 & 46.20 \\
$\operatorname{Exp}(1)$ & 79.80 & 99.80 & 99.20 & 90.60 & 80.00 & 95.00 & 96.80 & 76.00 \\
$\mathrm{~L}(0,1,1.4, .25)$ & 87.80 & 72.60 & 82.00 & 40.40 & 67.40 & 53.80 & 63.40 & 27.40 \\
$\mathrm{~L}(0,1,3,1)$ & 95.00 & 87.60 & 91.20 & 62.40 & 76.00 & 74.00 & 78.40 & 43.40 \\
$\mathrm{~L}(0,-1,-.0075,-.03)$ & 67.60 & 96.80 & 95.60 & 52.00 & 76.80 & 83.00 & 88.00 & 35.80 \\
$\mathrm{~L}(0,-1,-.1,-.18)$ & 24.00 & 55.20 & 46.40 & 19.40 & 45.00 & 43.20 & 44.60 & 15.40 \\
$\mathrm{~L}(0,-1,-.001,-.13)$ & 63.40 & 99.80 & 97.40 & 96.80 & 86.60 & 99.80 & 99.80 & 81.80 \\
\hline
\end{tabular}

Notes: Nominal size is 5\%. Sample size is 100 and the number of replications is 500 . $\mathrm{H}(\mathrm{BN}), \mathrm{H}(\mathrm{CCK}), \mathrm{H}(\mathrm{PB}), \mathrm{K}(\mathrm{BN}), \mathrm{K}(\mathrm{CCK})$, and $\mathrm{K}(\mathrm{PB})$ denote $\mathrm{H}$ and $\mathrm{K}$ tests with $\phi=\phi^{B N}, \phi^{C C K}$, and $\phi^{P B}$. $\mathrm{HQ}(\mathrm{PB})$ and $\mathrm{KQ}(\mathrm{PB})$ are the modified $\mathrm{H}$ and $\mathrm{K}$ tests with $\phi^{P B}$.

Table 2: Simulation results with a positive outlier

(a) Empirical Sizes

\begin{tabular}{lllllllll}
\hline & $\mathrm{H}(\mathrm{BN})$ & $\mathrm{H}(\mathrm{CCK})$ & $\mathrm{H}(\mathrm{PB})$ & $\mathrm{HQ}(\mathrm{PB})$ & $\mathrm{K}(\mathrm{BN})$ & $\mathrm{K}(\mathrm{CCK})$ & $\mathrm{K}(\mathrm{PB})$ & $\mathrm{KQ}(\mathrm{PB})$ \\
\hline $\mathrm{G}(0,1)$ & 0.00 & 0.00 & 0.00 & 5.40 & 0.00 & 3.00 & 0.80 & 3.20 \\
$\mathrm{t}(5)$ & 0.00 & 0.00 & 0.00 & 4.20 & 0.00 & 5.40 & 2.80 & 4.00 \\
$\mathrm{~L}(0, .19754, .134915, .134915)$ & 0.00 & 0.40 & 0.00 & 3.40 & 0.00 & 3.40 & 1.00 & 2.40 \\
$\mathrm{~L}(0,-1,-.08,-.08)$ & 0.00 & 0.00 & 0.00 & 4.60 & 0.00 & 5.00 & 4.00 & 3.40 \\
$\mathrm{~L}(0 .-1,-.24,-.24)$ & 0.00 & 1.20 & 0.40 & 5.80 & 2.60 & 6.60 & 7.00 & 2.60 \\
\hline
\end{tabular}

(b) Empirical Powers

\begin{tabular}{lllllllll}
\hline & $\mathrm{H}(\mathrm{BN})$ & $\mathrm{H}(\mathrm{CCK})$ & $\mathrm{H}(\mathrm{PB})$ & $\mathrm{HQ}(\mathrm{PB})$ & $\mathrm{K}(\mathrm{BN})$ & $\mathrm{K}(\mathrm{CCK})$ & $\mathrm{K}(\mathrm{PB})$ & $\mathrm{KQ}(\mathrm{PB})$ \\
\hline $\operatorname{Logn}(0,1)$ & 4.20 & 53.60 & 26.60 & 95.00 & 0.00 & 69.40 & 89.20 & 46.20 \\
$\operatorname{Exp}(1)$ & 0.00 & 0.60 & 0.00 & 95.60 & 0.00 & 87.20 & 97.40 & 77.40 \\
$\mathrm{~L}(0,1,1.4, .25)$ & 38.20 & 46.40 & 42.60 & 35.80 & 25.60 & 28.80 & 28.40 & 23.20 \\
$\mathrm{~L}(0,1,3,1)$ & 19.60 & 81.00 & 50.80 & 65.20 & 18.60 & 74.60 & 69.60 & 48.00 \\
$\mathrm{~L}(0,-1,-.0075,-.03)$ & 0.00 & 0.00 & 0.00 & 57.40 & 0.00 & 77.20 & 68.80 & 40.20 \\
$\mathrm{~L}(0,-1,-.1,-.18)$ & 0.00 & 2.80 & 0.00 & 35.60 & 0.60 & 48.60 & 44.40 & 20.60 \\
$\mathrm{~L}(0,-1,-.001,-.13)$ & 0.00 & 1.20 & 0.00 & 96.60 & 1.00 & 86.00 & 98.80 & 82.00 \\
\hline
\end{tabular}

Notes: Cf. Table 1. 
Table 3: Simulation results with a negative outlier

(a) Empirical Sizes

\begin{tabular}{|c|c|c|c|c|c|c|c|c|}
\hline & $\mathrm{H}(\mathrm{BN})$ & $\mathrm{H}(\mathrm{CCK})$ & $\mathrm{H}(\mathrm{PB})$ & $\mathrm{HQ}(\mathrm{PB})$ & $\mathrm{K}(\mathrm{BN})$ & $\mathrm{K}(\mathrm{CCK})$ & $\mathrm{K}(\mathrm{PB})$ & $\mathrm{KQ}(\mathrm{PB})$ \\
\hline $\mathrm{G}(0,1)$ & 0.00 & 0.60 & 0.20 & 3.60 & 0.00 & 3.60 & 0.80 & 1.80 \\
\hline $\mathrm{t}(5)$ & 0.00 & 0.60 & 0.00 & 3.40 & 0.00 & 2.80 & 1.60 & 2.60 \\
\hline $\mathrm{L}(0, .19754, .134915, .134915)$ & 0.00 & 0.60 & 0.00 & 5.40 & 0.00 & 4.20 & 1.20 & 2.60 \\
\hline $\mathrm{L}(0,-1,-.08,-.08)$ & 0.00 & 0.40 & 0.00 & 3.60 & 0.40 & 3.80 & 2.60 & 2.80 \\
\hline $\mathrm{L}(0 .-1,-.24,-.24)$ & 0.00 & 0.40 & 0.00 & 5.20 & 1.80 & 6.60 & 5.80 & 4.20 \\
\hline
\end{tabular}

(b) Empirical Powers

\begin{tabular}{lllllllll}
\hline & $\mathrm{H}(\mathrm{BN})$ & $\mathrm{H}(\mathrm{CCK})$ & $\mathrm{H}(\mathrm{PB})$ & $\mathrm{HQ}(\mathrm{PB})$ & $\mathrm{K}(\mathrm{BN})$ & $\mathrm{K}(\mathrm{CCK})$ & $\mathrm{K}(\mathrm{PB})$ & $\mathrm{KQ}(\mathrm{PB})$ \\
\hline $\operatorname{Logn}(0,1)$ & 44.40 & 92.80 & 79.60 & 94.20 & 17.00 & 92.60 & 96.20 & 46.60 \\
$\operatorname{Exp}(1)$ & 13.80 & 99.80 & 92.20 & 94.60 & 19.60 & 97.00 & 97.80 & 79.20 \\
$\mathrm{~L}(0,1,1.4, .25)$ & 0.00 & 0.00 & 0.00 & 36.00 & 0.00 & 0.00 & 0.00 & 25.20 \\
$\mathrm{~L}(0,1,3,1)$ & 0.00 & 0.00 & 0.00 & 54.20 & 0.00 & 0.00 & 0.00 & 39.80 \\
$\mathrm{~L}(0,-1,-.0075,-.03)$ & 56.20 & 89.20 & 83.60 & 49.80 & 61.00 & 72.80 & 74.00 & 34.40 \\
$\mathrm{~L}(0,-1,-.1,-.18)$ & 0.80 & 7.00 & 2.80 & 18.00 & 4.00 & 6.00 & 3.60 & 11.40 \\
$\mathrm{~L}(0,-1,-.001,-.13)$ & 33.20 & 99.80 & 98.60 & 97.00 & 64.40 & 99.60 & 99.60 & 83.80 \\
\hline
\end{tabular}

Notes: Cf. Table 1 
Table 4: Descriptive statistics for bond returns with 1 day holding period

(a) Japan

\begin{tabular}{rrrrrrrrrr}
\hline & Mean(ys) & Med. & Mean & S.D. & Skew. & Kurt. & AC(1) & Bowley & Pearson \\
\hline 1 & 0.001 & -0.000 & 0.001 & 0.050 & 0.722 & 22.961 & 0.013 & 0.060 & 0.023 \\
2 & 0.001 & 0.000 & 0.001 & 0.141 & -0.175 & 14.301 & -0.009 & 0.035 & 0.008 \\
3 & 0.002 & 0.005 & 0.008 & 0.253 & -0.402 & 11.899 & 0.019 & 0.045 & 0.010 \\
4 & 0.004 & 0.013 & 0.015 & 0.391 & -0.478 & 11.102 & 0.029 & 0.039 & 0.004 \\
5 & 0.006 & 0.020 & 0.021 & 0.538 & -0.564 & 11.211 & 0.029 & 0.027 & 0.001 \\
6 & 0.008 & 0.028 & 0.026 & 0.682 & -0.638 & 11.566 & 0.028 & 0.030 & -0.003 \\
7 & 0.010 & 0.029 & 0.031 & 0.818 & -0.691 & 11.915 & 0.027 & 0.041 & 0.001 \\
8 & 0.011 & 0.033 & 0.034 & 0.947 & -0.727 & 12.202 & 0.028 & 0.035 & 0.002 \\
9 & 0.013 & 0.030 & 0.038 & 1.072 & -0.748 & 12.424 & 0.030 & 0.038 & 0.007 \\
10 & 0.014 & 0.033 & 0.040 & 1.193 & -0.760 & 12.593 & 0.033 & 0.053 & 0.006 \\
15 & 0.017 & 0.043 & 0.053 & 1.793 & -0.757 & 12.980 & 0.051 & 0.053 & 0.005 \\
\hline
\end{tabular}

(b) US

\begin{tabular}{rrrrrrrrrr}
\hline & Mean(ys) & Med. & Mean & S.D. & Skew. & Kurt. & AC $(1)$ & Bowley & Pearson \\
\hline 1 & 0.001 & -0.012 & 0.002 & 0.159 & 0.446 & 6.704 & 0.045 & 0.191 & 0.092 \\
2 & 0.003 & -0.010 & 0.012 & 0.387 & 0.094 & 5.546 & 0.043 & 0.141 & 0.057 \\
3 & 0.004 & -0.009 & 0.021 & 0.607 & -0.021 & 5.293 & 0.050 & 0.156 & 0.049 \\
4 & 0.006 & -0.007 & 0.028 & 0.812 & -0.100 & 5.162 & 0.054 & 0.141 & 0.043 \\
5 & 0.007 & 0.002 & 0.035 & 1.005 & -0.166 & 5.099 & 0.055 & 0.129 & 0.033 \\
6 & 0.008 & 0.013 & 0.041 & 1.189 & -0.221 & 5.078 & 0.054 & 0.085 & 0.023 \\
7 & 0.010 & 0.027 & 0.046 & 1.366 & -0.265 & 5.080 & 0.052 & 0.082 & 0.014 \\
8 & 0.011 & 0.039 & 0.051 & 1.538 & -0.299 & 5.093 & 0.050 & 0.063 & 0.008 \\
9 & 0.012 & 0.050 & 0.055 & 1.706 & -0.326 & 5.108 & 0.048 & 0.062 & 0.003 \\
10 & 0.013 & 0.070 & 0.059 & 1.871 & -0.345 & 5.118 & 0.046 & 0.037 & -0.006 \\
15 & 0.016 & 0.118 & 0.079 & 2.642 & -0.361 & 5.053 & 0.039 & 0.014 & -0.015 \\
\hline
\end{tabular}

(c) UK

\begin{tabular}{rrrrrrrrrr}
\hline & Mean(ys) & Med. & Mean & S.D. & Skew. & Kurt. & AC(1) & Bowley & Pearson \\
\hline 1 & -0.001 & -0.011 & -0.006 & 0.134 & -0.345 & 7.801 & 0.107 & 0.136 & 0.043 \\
2 & -0.001 & -0.011 & -0.003 & 0.281 & -0.227 & 5.861 & 0.101 & 0.109 & 0.028 \\
3 & -0.001 & -0.009 & -0.000 & 0.429 & -0.227 & 5.744 & 0.088 & 0.074 & 0.019 \\
4 & -0.002 & -0.005 & 0.003 & 0.573 & -0.215 & 5.841 & 0.082 & 0.059 & 0.013 \\
5 & -0.002 & -0.004 & 0.006 & 0.714 & -0.206 & 6.120 & 0.079 & 0.058 & 0.014 \\
6 & -0.002 & 0.003 & 0.009 & 0.853 & -0.212 & 6.485 & 0.077 & 0.026 & 0.007 \\
7 & -0.002 & 0.005 & 0.012 & 0.992 & -0.231 & 6.827 & 0.076 & 0.024 & 0.007 \\
8 & -0.002 & 0.011 & 0.015 & 1.129 & -0.259 & 7.087 & 0.074 & 0.021 & 0.003 \\
9 & -0.002 & 0.002 & 0.017 & 1.265 & -0.287 & 7.250 & 0.073 & 0.037 & 0.012 \\
10 & -0.003 & -0.001 & 0.020 & 1.400 & -0.309 & 7.331 & 0.073 & 0.050 & 0.015 \\
15 & -0.004 & 0.001 & 0.034 & 2.066 & -0.276 & 7.245 & 0.075 & 0.032 & 0.016 \\
\hline
\end{tabular}


Table 4: (Continued) Descriptive statistics for bond returns with 1 day holding period

(d) Canada

\begin{tabular}{rrrrrrrrrr}
\hline & Mean(ys) & Med. & Mean & S.D. & Skew. & Kurt. & $\mathrm{AC}(1)$ & Bowley & Pearson \\
\hline 1 & 0.003 & -0.008 & -0.003 & 0.163 & -0.642 & 10.240 & 0.071 & 0.145 & 0.033 \\
2 & 0.005 & -0.004 & 0.002 & 0.323 & -0.619 & 9.480 & 0.081 & 0.119 & 0.020 \\
3 & 0.007 & 0.000 & 0.008 & 0.476 & -0.396 & 7.569 & 0.082 & 0.105 & 0.015 \\
4 & 0.009 & 0.003 & 0.013 & 0.625 & -0.289 & 6.853 & 0.081 & 0.109 & 0.015 \\
5 & 0.010 & 0.005 & 0.018 & 0.772 & -0.275 & 6.435 & 0.082 & 0.101 & 0.016 \\
6 & 0.011 & 0.012 & 0.023 & 0.919 & -0.251 & 6.195 & 0.082 & 0.082 & 0.012 \\
7 & 0.011 & 0.019 & 0.028 & 1.063 & -0.198 & 6.208 & 0.081 & 0.073 & 0.009 \\
8 & 0.012 & 0.026 & 0.033 & 1.201 & -0.143 & 6.335 & 0.079 & 0.070 & 0.006 \\
9 & 0.013 & 0.029 & 0.038 & 1.332 & -0.107 & 6.411 & 0.076 & 0.063 & 0.007 \\
10 & 0.013 & 0.039 & 0.044 & 1.457 & -0.093 & 6.371 & 0.072 & 0.055 & 0.003 \\
15 & 0.015 & 0.056 & 0.068 & 2.035 & -0.120 & 6.189 & 0.047 & 0.042 & 0.006 \\
\hline
\end{tabular}

(e) Germany

\begin{tabular}{rrrrrrrrrr}
\hline & Mean(ys) & Med. & Mean & S.D. & Skew. & Kurt. & AC(1) & Bowley & Pearson \\
\hline 1 & 0.002 & -0.006 & -0.002 & 0.117 & -0.083 & 8.353 & -0.046 & 0.066 & 0.033 \\
2 & 0.004 & 0.002 & 0.003 & 0.276 & -0.325 & 6.824 & -0.017 & 0.034 & 0.002 \\
3 & 0.006 & 0.010 & 0.008 & 0.447 & -0.389 & 6.368 & -0.027 & 0.040 & -0.005 \\
4 & 0.008 & 0.012 & 0.014 & 0.613 & -0.441 & 6.201 & -0.039 & 0.069 & 0.003 \\
5 & 0.009 & 0.017 & 0.019 & 0.771 & -0.497 & 6.350 & -0.050 & 0.068 & 0.003 \\
6 & 0.011 & 0.018 & 0.024 & 0.924 & -0.550 & 6.750 & -0.059 & 0.070 & 0.007 \\
7 & 0.012 & 0.022 & 0.029 & 1.072 & -0.600 & 7.351 & -0.066 & 0.060 & 0.007 \\
8 & 0.013 & 0.023 & 0.034 & 1.217 & -0.645 & 8.101 & -0.072 & 0.056 & 0.009 \\
9 & 0.014 & 0.030 & 0.038 & 1.360 & -0.688 & 8.933 & -0.077 & 0.051 & 0.006 \\
10 & 0.015 & 0.029 & 0.043 & 1.506 & -0.727 & 9.781 & -0.083 & 0.054 & 0.009 \\
15 & 0.018 & 0.031 & 0.064 & 2.296 & -0.835 & 12.682 & -0.106 & 0.081 & 0.014 \\
\hline
\end{tabular}

Notes: Column 1 shows the maturities. Column 2 reports the sample mean of yield spread. Columns 3-10 report the sample median, sample standard deviation, sample skewness, sample kurtosis, sample autocorrelation of order 1, estimates of Bowley and Pearson coefficients, respectively. 
Table 5: Descriptive statistics for bond returns with 1 week holding period

(a) Japan

\begin{tabular}{rrrrrrrrrr}
\hline & Mean(ys) & Med. & Mean & S.D. & Skew. & Kurt. & AC(1) & Bowley & Pearson \\
\hline 1 & 0.001 & 0.001 & 0.001 & 0.017 & 0.537 & 9.036 & -0.001 & -0.024 & 0.022 \\
2 & 0.001 & 0.001 & 0.001 & 0.046 & 0.622 & 8.143 & -0.053 & -0.045 & 0.011 \\
3 & 0.002 & 0.007 & 0.007 & 0.084 & 0.467 & 8.093 & 0.010 & -0.012 & 0.004 \\
4 & 0.004 & 0.018 & 0.014 & 0.131 & 0.135 & 7.758 & 0.050 & -0.091 & -0.033 \\
5 & 0.006 & 0.032 & 0.019 & 0.182 & -0.127 & 7.718 & 0.070 & -0.095 & -0.070 \\
6 & 0.008 & 0.038 & 0.023 & 0.232 & -0.311 & 7.864 & 0.080 & -0.101 & -0.065 \\
7 & 0.010 & 0.049 & 0.026 & 0.280 & -0.440 & 8.064 & 0.087 & -0.130 & -0.082 \\
8 & 0.011 & 0.051 & 0.028 & 0.326 & -0.532 & 8.249 & 0.091 & -0.108 & -0.071 \\
9 & 0.012 & 0.064 & 0.030 & 0.370 & -0.598 & 8.390 & 0.093 & -0.143 & -0.093 \\
10 & 0.014 & 0.068 & 0.031 & 0.414 & -0.645 & 8.480 & 0.094 & -0.131 & -0.091 \\
15 & 0.017 & 0.087 & 0.034 & 0.634 & -0.737 & 8.466 & 0.091 & -0.141 & -0.084 \\
\hline
\end{tabular}

(b) US

\begin{tabular}{rrrrrrrrrr}
\hline & Mean(ys) & Med. & Mean & S.D. & Skew. & Kurt. & $\mathrm{AC}(1)$ & Bowley & Pearson \\
\hline 1 & 0.001 & 0.002 & 0.005 & 0.054 & 0.710 & 8.007 & -0.098 & 0.028 & 0.044 \\
2 & 0.003 & 0.008 & 0.011 & 0.133 & 0.113 & 5.322 & -0.070 & 0.040 & 0.020 \\
3 & 0.004 & 0.012 & 0.016 & 0.212 & -0.106 & 4.639 & -0.056 & 0.063 & 0.020 \\
4 & 0.006 & 0.012 & 0.021 & 0.284 & -0.253 & 4.330 & -0.051 & 0.094 & 0.030 \\
5 & 0.007 & 0.016 & 0.025 & 0.352 & -0.369 & 4.210 & -0.051 & 0.101 & 0.024 \\
6 & 0.008 & 0.024 & 0.028 & 0.417 & -0.462 & 4.185 & -0.054 & 0.087 & 0.010 \\
7 & 0.010 & 0.028 & 0.031 & 0.479 & -0.532 & 4.198 & -0.058 & 0.103 & 0.007 \\
8 & 0.011 & 0.042 & 0.034 & 0.539 & -0.581 & 4.216 & -0.063 & 0.060 & -0.015 \\
9 & 0.012 & 0.062 & 0.036 & 0.597 & -0.612 & 4.219 & -0.067 & 0.015 & -0.044 \\
10 & 0.013 & 0.078 & 0.038 & 0.655 & -0.627 & 4.199 & -0.071 & -0.010 & -0.062 \\
15 & 0.016 & 0.124 & 0.046 & 0.923 & -0.569 & 3.855 & -0.074 & -0.048 & -0.084 \\
\hline
\end{tabular}

(c) UK

\begin{tabular}{rrrrrrrrrr}
\hline & Mean(ys) & Med. & Mean & S.D. & Skew. & Kurt. & $\mathrm{AC}(1)$ & Bowley & Pearson \\
\hline 1 & -0.001 & 0.001 & 0.001 & 0.049 & -0.210 & 4.315 & 0.010 & 0.023 & -0.007 \\
2 & -0.001 & 0.006 & 0.003 & 0.103 & -0.216 & 3.971 & -0.007 & -0.035 & -0.029 \\
3 & -0.001 & 0.008 & 0.005 & 0.157 & -0.196 & 3.984 & -0.020 & -0.040 & -0.020 \\
4 & -0.002 & 0.012 & 0.007 & 0.210 & -0.181 & 4.028 & -0.033 & -0.045 & -0.023 \\
5 & -0.002 & 0.013 & 0.009 & 0.262 & -0.190 & 4.145 & -0.044 & -0.023 & -0.014 \\
6 & -0.002 & 0.015 & 0.011 & 0.313 & -0.225 & 4.401 & -0.055 & -0.036 & -0.012 \\
7 & -0.002 & 0.013 & 0.013 & 0.364 & -0.275 & 4.809 & -0.065 & -0.019 & 0.001 \\
8 & -0.002 & 0.016 & 0.015 & 0.415 & -0.329 & 5.316 & -0.074 & -0.010 & -0.001 \\
9 & -0.002 & 0.017 & 0.017 & 0.464 & -0.378 & 5.847 & -0.083 & -0.014 & 0.001 \\
10 & -0.003 & 0.023 & 0.019 & 0.513 & -0.417 & 6.338 & -0.093 & -0.039 & -0.008 \\
15 & -0.004 & 0.024 & 0.027 & 0.754 & -0.426 & 7.451 & -0.145 & -0.012 & 0.005 \\
\hline
\end{tabular}


Table 5: (Continued) Descriptive statistics for bond returns with 1 week holding period

(d) Canada

\begin{tabular}{rrrrrrrrrr}
\hline & Mean(ys) & Med. & Mean & S.D. & Skew. & Kurt. & AC(1) & Bowley & Pearson \\
\hline 1 & 0.003 & 0.006 & 0.006 & 0.058 & -0.077 & 4.348 & -0.071 & 0.055 & 0.001 \\
2 & 0.005 & 0.010 & 0.011 & 0.117 & -0.153 & 4.570 & -0.043 & 0.080 & 0.011 \\
3 & 0.007 & 0.012 & 0.015 & 0.175 & -0.273 & 4.859 & -0.024 & 0.064 & 0.019 \\
4 & 0.009 & 0.017 & 0.019 & 0.233 & -0.370 & 5.023 & -0.016 & 0.047 & 0.006 \\
5 & 0.010 & 0.018 & 0.022 & 0.290 & -0.433 & 5.038 & -0.016 & 0.083 & 0.014 \\
6 & 0.011 & 0.023 & 0.025 & 0.346 & -0.463 & 4.944 & -0.020 & 0.048 & 0.004 \\
7 & 0.011 & 0.036 & 0.028 & 0.399 & -0.472 & 4.794 & -0.026 & 0.041 & -0.022 \\
8 & 0.012 & 0.047 & 0.031 & 0.449 & -0.467 & 4.629 & -0.033 & 0.021 & -0.036 \\
9 & 0.013 & 0.063 & 0.033 & 0.496 & -0.458 & 4.472 & -0.038 & -0.025 & -0.060 \\
10 & 0.013 & 0.071 & 0.036 & 0.539 & -0.450 & 4.334 & -0.043 & -0.045 & -0.065 \\
15 & 0.015 & 0.097 & 0.051 & 0.726 & -0.471 & 4.072 & -0.053 & -0.074 & -0.064 \\
\hline
\end{tabular}

(e) Germany

\begin{tabular}{rrrrrrrrrr}
\hline & Mean(ys) & Med. & Mean & S.D. & Skew. & Kurt. & AC(1) & Bowley & Pearson \\
\hline 1 & 0.002 & 0.001 & 0.004 & 0.038 & 0.060 & 4.566 & 0.007 & 0.083 & 0.055 \\
2 & 0.004 & 0.008 & 0.008 & 0.093 & -0.173 & 3.976 & -0.009 & 0.064 & -0.006 \\
3 & 0.006 & 0.012 & 0.012 & 0.150 & -0.225 & 3.502 & -0.012 & 0.037 & -0.002 \\
4 & 0.008 & 0.019 & 0.016 & 0.206 & -0.265 & 3.418 & -0.014 & 0.040 & -0.012 \\
5 & 0.009 & 0.025 & 0.020 & 0.258 & -0.311 & 3.587 & -0.017 & 0.008 & -0.017 \\
6 & 0.011 & 0.041 & 0.024 & 0.308 & -0.360 & 3.895 & -0.021 & -0.056 & -0.056 \\
7 & 0.012 & 0.048 & 0.027 & 0.356 & -0.407 & 4.253 & -0.026 & -0.057 & -0.060 \\
8 & 0.013 & 0.052 & 0.030 & 0.402 & -0.449 & 4.596 & -0.030 & -0.031 & -0.055 \\
9 & 0.014 & 0.055 & 0.033 & 0.447 & -0.484 & 4.882 & -0.034 & -0.034 & -0.049 \\
10 & 0.015 & 0.056 & 0.036 & 0.491 & -0.509 & 5.094 & -0.038 & 0.008 & -0.042 \\
15 & 0.018 & 0.082 & 0.049 & 0.720 & -0.468 & 5.236 & -0.058 & -0.060 & -0.046 \\
\hline
\end{tabular}

Notes: Cf. Table 3. 
Table 6: Descriptive statistics for bond returns with 1 month holding period

(a) Japan

\begin{tabular}{rrrrrrrrrr}
\hline & Mean(ys) & Med. & Mean & S.D. & Skew. & Kurt. & AC $(1)$ & Bowley & Pearson \\
\hline 1 & 0.001 & 0.001 & 0.002 & 0.009 & -0.975 & 7.373 & 0.092 & 0.197 & 0.024 \\
2 & 0.001 & 0.002 & 0.001 & 0.022 & -1.246 & 9.588 & -0.026 & 0.035 & -0.055 \\
3 & 0.002 & 0.010 & 0.007 & 0.041 & -1.503 & 10.208 & 0.013 & -0.049 & -0.087 \\
4 & 0.004 & 0.020 & 0.013 & 0.064 & -1.634 & 10.206 & 0.028 & -0.052 & -0.102 \\
5 & 0.006 & 0.024 & 0.019 & 0.090 & -1.707 & 10.504 & 0.038 & 0.030 & -0.059 \\
6 & 0.008 & 0.032 & 0.023 & 0.115 & -1.745 & 10.940 & 0.051 & 0.007 & -0.074 \\
7 & 0.010 & 0.041 & 0.026 & 0.139 & -1.756 & 11.366 & 0.066 & -0.102 & -0.105 \\
8 & 0.011 & 0.044 & 0.029 & 0.162 & -1.746 & 11.714 & 0.081 & -0.105 & -0.096 \\
9 & 0.012 & 0.044 & 0.031 & 0.185 & -1.722 & 11.959 & 0.096 & -0.037 & -0.073 \\
10 & 0.014 & 0.042 & 0.032 & 0.207 & -1.689 & 12.104 & 0.109 & 0.081 & -0.050 \\
15 & 0.017 & 0.036 & 0.038 & 0.317 & -1.501 & 11.952 & 0.148 & 0.101 & 0.004 \\
\hline
\end{tabular}

(b) US

\begin{tabular}{rrrrrrrrrr}
\hline & Mean(ys) & Med. & Mean & S.D. & Skew. & Kurt. & $\mathrm{AC}(1)$ & Bowley & Pearson \\
\hline 1 & -0.001 & 0.000 & 0.003 & 0.024 & 0.938 & 4.652 & 0.129 & -0.056 & 0.098 \\
2 & 0.001 & 0.004 & 0.009 & 0.062 & 0.356 & 3.604 & 0.102 & 0.045 & 0.080 \\
3 & 0.002 & 0.007 & 0.015 & 0.101 & 0.075 & 3.417 & 0.077 & 0.138 & 0.083 \\
4 & 0.004 & 0.012 & 0.020 & 0.138 & -0.074 & 3.419 & 0.060 & 0.173 & 0.063 \\
5 & 0.005 & 0.017 & 0.025 & 0.170 & -0.176 & 3.534 & 0.049 & 0.148 & 0.048 \\
6 & 0.007 & 0.026 & 0.029 & 0.200 & -0.266 & 3.718 & 0.042 & 0.066 & 0.014 \\
7 & 0.008 & 0.022 & 0.032 & 0.227 & -0.354 & 3.940 & 0.037 & 0.068 & 0.046 \\
8 & 0.009 & 0.030 & 0.035 & 0.252 & -0.444 & 4.176 & 0.034 & 0.068 & 0.022 \\
9 & 0.010 & 0.043 & 0.038 & 0.276 & -0.533 & 4.410 & 0.031 & 0.034 & -0.018 \\
10 & 0.011 & 0.046 & 0.040 & 0.299 & -0.620 & 4.628 & 0.028 & 0.008 & -0.021 \\
15 & 0.014 & 0.093 & 0.049 & 0.405 & -0.887 & 5.208 & 0.007 & -0.115 & -0.107 \\
\hline
\end{tabular}

(c) UK

\begin{tabular}{rrrrrrrrrr}
\hline & Mean(ys) & Med. & Mean & S.D. & Skew. & Kurt. & AC $(1)$ & Bowley & Pearson \\
\hline 1 & -0.002 & 0.002 & -0.000 & 0.022 & -0.285 & 3.361 & 0.150 & -0.133 & -0.074 \\
2 & -0.002 & 0.006 & 0.002 & 0.048 & -0.352 & 3.047 & 0.149 & -0.171 & -0.088 \\
3 & -0.002 & 0.013 & 0.004 & 0.073 & -0.332 & 2.948 & 0.144 & -0.195 & -0.124 \\
4 & -0.003 & 0.022 & 0.006 & 0.098 & -0.302 & 2.952 & 0.135 & -0.242 & -0.164 \\
5 & -0.003 & 0.024 & 0.008 & 0.121 & -0.266 & 3.022 & 0.121 & -0.203 & -0.132 \\
6 & -0.003 & 0.033 & 0.010 & 0.144 & -0.223 & 3.112 & 0.105 & -0.254 & -0.160 \\
7 & -0.003 & 0.029 & 0.013 & 0.165 & -0.176 & 3.188 & 0.088 & -0.177 & -0.103 \\
8 & -0.003 & 0.023 & 0.015 & 0.185 & -0.127 & 3.232 & 0.072 & -0.083 & -0.047 \\
9 & -0.003 & 0.020 & 0.017 & 0.204 & -0.082 & 3.238 & 0.057 & -0.027 & -0.016 \\
10 & -0.004 & 0.017 & 0.019 & 0.223 & -0.042 & 3.211 & 0.044 & 0.022 & 0.008 \\
15 & -0.004 & 0.025 & 0.029 & 0.306 & 0.094 & 2.869 & 0.002 & 0.058 & 0.014 \\
\hline
\end{tabular}


Table 6: (Continued) Descriptive statistics for bond returns with 1 month holding period

(d) Canada

\begin{tabular}{rrrrrrrrrr}
\hline & Mean(ys) & Med. & Mean & S.D. & Skew. & Kurt. & AC(1) & Bowley & Pearson \\
\hline 1 & 0.001 & 0.001 & 0.004 & 0.024 & 0.667 & 4.744 & 0.063 & 0.157 & 0.110 \\
2 & 0.003 & 0.003 & 0.009 & 0.051 & 0.604 & 4.719 & 0.060 & 0.168 & 0.114 \\
3 & 0.005 & -0.001 & 0.013 & 0.078 & 0.460 & 4.395 & 0.054 & 0.360 & 0.176 \\
4 & 0.006 & -0.000 & 0.017 & 0.105 & 0.336 & 4.047 & 0.051 & 0.328 & 0.161 \\
5 & 0.008 & 0.007 & 0.020 & 0.130 & 0.245 & 3.767 & 0.045 & 0.263 & 0.098 \\
6 & 0.008 & 0.007 & 0.024 & 0.154 & 0.185 & 3.567 & 0.036 & 0.246 & 0.108 \\
7 & 0.009 & 0.018 & 0.027 & 0.175 & 0.151 & 3.431 & 0.024 & 0.156 & 0.053 \\
8 & 0.010 & 0.020 & 0.031 & 0.193 & 0.133 & 3.345 & 0.010 & 0.114 & 0.054 \\
9 & 0.011 & 0.027 & 0.034 & 0.210 & 0.125 & 3.296 & -0.003 & 0.061 & 0.032 \\
10 & 0.011 & 0.032 & 0.037 & 0.225 & 0.120 & 3.273 & -0.016 & 0.042 & 0.023 \\
15 & 0.013 & 0.058 & 0.054 & 0.294 & 0.124 & 3.182 & -0.059 & -0.006 & -0.012 \\
\hline
\end{tabular}

(e) Germany

\begin{tabular}{rrrrrrrrrr}
\hline & Mean(ys) & Med. & Mean & S.D. & Skew. & Kurt. & AC $(1)$ & Bowley & Pearson \\
\hline 1 & 0.001 & 0.000 & 0.002 & 0.017 & 0.065 & 3.135 & 0.103 & 0.217 & 0.128 \\
2 & 0.003 & 0.003 & 0.006 & 0.044 & 0.017 & 2.504 & 0.125 & 0.148 & 0.082 \\
3 & 0.005 & 0.016 & 0.011 & 0.070 & -0.035 & 2.533 & 0.141 & -0.138 & -0.070 \\
4 & 0.007 & 0.021 & 0.015 & 0.095 & -0.073 & 2.636 & 0.161 & -0.128 & -0.057 \\
5 & 0.008 & 0.039 & 0.019 & 0.117 & -0.101 & 2.721 & 0.175 & -0.297 & -0.168 \\
6 & 0.009 & 0.052 & 0.023 & 0.137 & -0.122 & 2.758 & 0.183 & -0.361 & -0.217 \\
7 & 0.011 & 0.056 & 0.026 & 0.156 & -0.136 & 2.743 & 0.183 & -0.312 & -0.193 \\
8 & 0.012 & 0.062 & 0.029 & 0.175 & -0.142 & 2.687 & 0.178 & -0.339 & -0.191 \\
9 & 0.013 & 0.071 & 0.032 & 0.193 & -0.139 & 2.611 & 0.168 & -0.362 & -0.206 \\
10 & 0.013 & 0.072 & 0.035 & 0.210 & -0.129 & 2.530 & 0.156 & -0.348 & -0.179 \\
15 & 0.016 & 0.050 & 0.047 & 0.295 & -0.028 & 2.274 & 0.077 & -0.087 & -0.010 \\
\hline
\end{tabular}

Notes: Cf. Table 3. 
Table 7: Test results for bond returns with 1 day holding period

(a) Japan

\begin{tabular}{llllll}
\hline & $\mathrm{K}(\mathrm{BN})$ & $\mathrm{K}(\mathrm{CCK})$ & $\mathrm{K}(\mathrm{PB})$ & $\mathrm{KQ}(\mathrm{PB})$ & $\mathrm{HQ}(\mathrm{PB})$ \\
\hline 1 & 44.911 & 5.964 & 2.817 & 10.819 & $6.623^{*}$ \\
2 & 9.572 & 0.813 & 0.788 & 2.056 & 1.163 \\
3 & 22.570 & 0.000 & 1.364 & 2.622 & 2.092 \\
4 & 27.692 & 2.529 & 5.272 & 2.699 & 1.427 \\
5 & 41.912 & 4.530 & 8.761 & 2.765 & 1.327 \\
6 & $68.410^{*}$ & 5.181 & 11.216 & 2.395 & 0.709 \\
7 & $108.474^{*}$ & 4.953 & 12.696 & 4.049 & 1.873 \\
8 & $158.245^{*}$ & 4.449 & 13.636 & 6.989 & 1.971 \\
9 & $204.822^{*}$ & 4.001 & 14.400 & 10.056 & $4.177^{*}$ \\
10 & $233.606^{*}$ & 3.725 & 15.201 & 8.816 & 3.685 \\
15 & $192.655^{*}$ & 4.048 & 20.630 & 4.198 & 3.235 \\
\hline
\end{tabular}

(b) US

\begin{tabular}{llllll}
\hline & $\mathrm{K}(\mathrm{BN})$ & $\mathrm{K}(\mathrm{CCK})$ & $\mathrm{K}(\mathrm{PB})$ & $\mathrm{KQ}(\mathrm{PB})$ & $\mathrm{HQ}(\mathrm{PB})$ \\
\hline 1 & 15.082 & $64.913^{*}$ & 39.419 & $248.979^{*}$ & $47.687^{*}$ \\
2 & 1.258 & 28.200 & 11.894 & $67.854^{*}$ & $18.296^{*}$ \\
3 & 0.091 & 12.226 & 3.249 & $85.314^{*}$ & $18.206^{*}$ \\
4 & 2.585 & 4.783 & 0.321 & $58.761^{*}$ & $16.978^{*}$ \\
5 & 8.571 & 1.386 & 0.172 & $141.625^{*}$ & $11.835^{*}$ \\
6 & 17.560 & 0.119 & 1.453 & $74.673^{*}$ & $7.589^{*}$ \\
7 & 28.216 & 0.150 & 3.523 & $54.093^{*}$ & $4.046^{*}$ \\
8 & 38.609 & 0.993 & 5.970 & 42.924 & 2.684 \\
9 & $46.845^{*}$ & 2.198 & 8.467 & 43.846 & 1.723 \\
10 & $51.980^{*}$ & 3.635 & 10.953 & 7.272 & 0.401 \\
15 & $51.257^{*}$ & 10.900 & 20.538 & 0.266 & 0.014 \\
\hline
\end{tabular}

(c) UK

\begin{tabular}{llllll}
\hline & $\mathrm{K}(\mathrm{BN})$ & $\mathrm{K}(\mathrm{CCK})$ & $\mathrm{K}(\mathrm{PB})$ & $\mathrm{KQ}(\mathrm{PB})$ & $\mathrm{HQ}(\mathrm{PB})$ \\
\hline 1 & $66.532^{*}$ & 28.447 & 2.760 & $119.668^{*}$ & $15.147^{*}$ \\
2 & $146.980^{*}$ & 0.691 & 3.630 & $78.034^{*}$ & $9.935^{*}$ \\
3 & $107.961^{*}$ & 0.007 & 6.377 & 32.333 & $5.667^{*}$ \\
4 & $79.928^{*}$ & 0.055 & 6.015 & 10.302 & 3.190 \\
5 & $59.661^{*}$ & 0.002 & 4.192 & 12.606 & 3.419 \\
6 & 45.321 & 0.035 & 2.875 & 3.855 & 1.099 \\
7 & 37.142 & 0.064 & 2.025 & 2.132 & 0.890 \\
8 & 32.997 & 0.318 & 1.193 & 0.586 & 0.273 \\
9 & 30.784 & 1.003 & 0.560 & 4.157 & 1.843 \\
10 & 29.287 & 2.043 & 0.177 & 6.011 & 2.648 \\
15 & 21.175 & 6.674 & 2.902 & 3.329 & 1.851 \\
\hline
\end{tabular}


Table 7: (Continued) Test results for bond returns with 1 day holding period

(d) Canada

\begin{tabular}{llllll}
\hline & $\mathrm{K}(\mathrm{BN})$ & $\mathrm{K}(\mathrm{CCK})$ & $\mathrm{K}(\mathrm{PB})$ & $\mathrm{KQ}(\mathrm{PB})$ & $\mathrm{HQ}(\mathrm{PB})$ \\
\hline 1 & $92.096^{*}$ & 0.096 & 11.884 & $170.929^{*}$ & $15.096^{*}$ \\
2 & $151.248^{*}$ & 0.285 & 16.187 & $87.741^{*}$ & $7.713^{*}$ \\
3 & $55.536^{*}$ & 0.077 & 5.120 & $62.162^{*}$ & $4.257^{*}$ \\
4 & 15.544 & 0.001 & 2.487 & 32.871 & 3.826 \\
5 & 14.133 & 0.021 & 2.747 & 12.622 & $4.807^{*}$ \\
6 & 13.133 & 0.136 & 2.954 & 17.331 & 3.017 \\
7 & 8.709 & 0.378 & 2.857 & 10.733 & 1.939 \\
8 & 4.813 & 0.683 & 2.696 & 13.760 & 1.283 \\
9 & 2.998 & 0.833 & 2.505 & 7.409 & 1.431 \\
10 & 2.782 & 0.820 & 2.241 & 3.862 & 0.608 \\
15 & 15.089 & 0.516 & 1.307 & 4.983 & 0.715 \\
\hline
\end{tabular}

\begin{tabular}{llllll}
\hline \multicolumn{5}{c}{$(\mathrm{e})$ Germany } \\
\hline & $\mathrm{K}(\mathrm{BN})$ & $\mathrm{K}(\mathrm{CCK})$ & $\mathrm{K}(\mathrm{PB})$ & $\mathrm{KQ}(\mathrm{PB})$ & $\mathrm{HQ}(\mathrm{PB})$ \\
\hline 1 & 0.194 & 12.098 & 3.062 & $46.684^{*}$ & $6.222^{*}$ \\
2 & 16.488 & 0.057 & 1.817 & 1.393 & 0.524 \\
3 & $56.508^{*}$ & 1.754 & 6.939 & 1.097 & 0.350 \\
4 & $73.985^{*}$ & 2.579 & 9.237 & $52.836^{*}$ & 2.310 \\
5 & $70.982^{*}$ & 3.339 & 11.032 & 7.666 & 2.336 \\
6 & $58.177^{*}$ & 4.543 & 13.667 & 21.871 & 3.623 \\
7 & 44.889 & 6.192 & 16.967 & 17.054 & 3.756 \\
8 & 35.561 & 8.334 & 20.612 & 22.386 & 4.332 \\
9 & 29.928 & 10.652 & 24.676 & 9.824 & 3.008 \\
10 & 26.777 & 12.661 & 29.122 & 9.677 & 3.662 \\
15 & 25.358 & 13.358 & 36.939 & 23.618 & $5.288^{*}$ \\
\hline
\end{tabular}

Notes: $\mathrm{K}(\mathrm{BN}), \mathrm{K}(\mathrm{CCK})$, and $\mathrm{K}(\mathrm{PB})$ denote $\mathrm{K}$ tests with $\phi=\phi^{B N}, \phi^{C C K}$, and $\phi^{P B}$, respectively. $\mathrm{HQ}(\mathrm{PB})$ and $\mathrm{KQ}(\mathrm{PB})$ are the modified $\mathrm{H}$ and $\mathrm{K}$ tests with $\phi^{P B}$. Significance level at $5 \%$ is 45.4 for $K($.$) and \mathrm{KQ}(\mathrm{PB})$ and 3.84 for $\mathrm{HQ}(\mathrm{PB})$. The superscript $*$ indicates significance at $5 \%$ level. The number of observations for daily, weekly and monthly are 2563, 543 and 125 . 
Table 8: Test results for bond returns with 1 week holding period

(a) Japan

\begin{tabular}{llllll}
\hline & $\mathrm{K}(\mathrm{BN})$ & $\mathrm{K}(\mathrm{CCK})$ & $\mathrm{K}(\mathrm{PB})$ & $\mathrm{KQ}(\mathrm{PB})$ & $\mathrm{HQ}(\mathrm{PB})$ \\
\hline 1 & $127.781^{*}$ & 26.609 & 42.811 & 7.636 & 0.226 \\
2 & $260.457^{*}$ & 23.644 & $55.268^{*}$ & 0.253 & 0.008 \\
3 & $142.965^{*}$ & 3.155 & 21.309 & 0.195 & 0.060 \\
4 & 12.179 & 41.010 & 5.692 & 7.670 & 1.493 \\
5 & 8.111 & $89.134^{*}$ & 35.628 & $57.404^{*}$ & $5.526^{*}$ \\
6 & 43.536 & $90.458^{*}$ & $54.714^{*}$ & $71.238^{*}$ & 3.826 \\
7 & $93.961^{*}$ & $87.070^{*}$ & $66.200^{*}$ & $177.510^{*}$ & $6.720^{*}$ \\
8 & $159.878^{*}$ & $81.101^{*}$ & $73.009^{*}$ & 41.134 & 3.525 \\
9 & $232.498^{*}$ & $75.316^{*}$ & $77.291^{*}$ & $68.582^{*}$ & $8.094^{*}$ \\
10 & $291.722^{*}$ & $71.048^{*}$ & $80.639^{*}$ & $82.929^{*}$ & $7.290^{*}$ \\
15 & $288.309^{*}$ & $65.528^{*}$ & $96.479^{*}$ & $29.260^{*}$ & $5.320^{*}$ \\
\hline
\end{tabular}

(b) US

\begin{tabular}{llllll}
\hline & $\mathrm{K}(\mathrm{BN})$ & $\mathrm{K}(\mathrm{CCK})$ & $\mathrm{K}(\mathrm{PB})$ & $\mathrm{KQ}(\mathrm{PB})$ & $\mathrm{HQ}(\mathrm{PB})$ \\
\hline 1 & $51.276^{*}$ & 12.871 & 17.711 & 9.323 & 1.071 \\
2 & 2.562 & 1.373 & 1.286 & 0.630 & 0.287 \\
3 & 1.850 & 0.150 & 0.009 & 1.816 & 0.548 \\
4 & 10.219 & 0.200 & 1.255 & 8.351 & 1.950 \\
5 & 23.865 & 1.923 & 4.707 & 12.708 & 1.982 \\
6 & 42.686 & 5.587 & 10.490 & 8.887 & 1.103 \\
7 & $65.023^{*}$ & 11.331 & 18.491 & 12.634 & 1.156 \\
8 & $87.581^{*}$ & 18.955 & 28.145 & 1.826 & 0.200 \\
9 & $106.521^{*}$ & 27.292 & 38.219 & 1.681 & 0.190 \\
10 & $119.176^{*}$ & 34.735 & $47.259^{*}$ & 11.005 & 1.028 \\
15 & $126.919^{*}$ & $49.405^{*}$ & $69.484^{*}$ & $54.894^{*}$ & 3.034 \\
\hline
\end{tabular}

(c) UK

\begin{tabular}{llllll}
\hline & $\mathrm{K}(\mathrm{BN})$ & $\mathrm{K}(\mathrm{CCK})$ & $\mathrm{K}(\mathrm{PB})$ & $\mathrm{KQ}(\mathrm{PB})$ & $\mathrm{HQ}(\mathrm{PB})$ \\
\hline 1 & 39.186 & 5.297 & 8.305 & 0.353 & 0.024 \\
2 & 40.701 & 8.297 & 10.817 & 3.735 & 0.392 \\
3 & 36.232 & 6.093 & 9.567 & 0.273 & 0.118 \\
4 & 32.169 & 6.026 & 9.692 & 0.373 & 0.184 \\
5 & 35.505 & 6.036 & 9.945 & 0.033 & 0.013 \\
6 & 42.999 & 5.565 & 9.551 & 0.028 & 0.005 \\
7 & $48.503^{*}$ & 4.165 & 8.139 & 1.612 & 0.113 \\
8 & $50.298^{*}$ & 2.206 & 5.948 & 0.486 & 0.047 \\
9 & $49.903^{*}$ & 0.592 & 3.536 & 0.852 & 0.054 \\
10 & $48.464^{*}$ & 0.000 & 1.488 & 0.563 & 0.028 \\
15 & 33.922 & 2.770 & 2.034 & 0.037 & 0.011 \\
\hline
\end{tabular}


Table 8: (Continued) Test results for bond returns with 1 week holding period

(d) Canada

\begin{tabular}{llllll}
\hline & $\mathrm{K}(\mathrm{BN})$ & $\mathrm{K}(\mathrm{CCK})$ & $\mathrm{K}(\mathrm{PB})$ & $\mathrm{KQ}(\mathrm{PB})$ & $\mathrm{HQ}(\mathrm{PB})$ \\
\hline 1 & 1.771 & 0.243 & 0.013 & 0.014 & 0.002 \\
2 & 5.626 & 1.694 & 0.141 & 2.792 & 0.143 \\
3 & 12.047 & 0.062 & 0.548 & 13.363 & 0.736 \\
4 & 18.805 & 0.736 & 2.831 & 4.348 & 0.277 \\
5 & 26.448 & 2.968 & 6.773 & 3.249 & 0.996 \\
6 & 35.032 & 8.438 & 14.175 & 3.431 & 0.635 \\
7 & 44.170 & 15.769 & 23.599 & 0.080 & 0.010 \\
8 & $53.996 *$ & 23.754 & 33.750 & 2.298 & 0.340 \\
9 & $65.326^{*}$ & 32.263 & 44.433 & 11.445 & 1.818 \\
10 & $79.075^{*}$ & 40.576 & $55.082^{*}$ & 13.115 & 2.275 \\
15 & $144.819^{*}$ & $50.680^{*}$ & $74.099^{*}$ & 16.178 & 1.790 \\
\hline
\end{tabular}

\begin{tabular}{llllll}
\multicolumn{5}{c}{$(\mathrm{e})$ Germany } \\
\hline & $\mathrm{K}(\mathrm{BN})$ & $\mathrm{K}(\mathrm{CCK})$ & $\mathrm{K}(\mathrm{PB})$ & $\mathrm{KQ}(\mathrm{PB})$ & $\mathrm{HQ}(\mathrm{PB})$ \\
\hline 1 & 0.506 & 1.816 & 1.240 & 6.465 & 2.856 \\
2 & 8.912 & 0.024 & 0.642 & 0.001 & 0.000 \\
3 & 17.521 & 1.053 & 3.078 & 0.215 & 0.137 \\
4 & 25.907 & 3.066 & 6.115 & 0.024 & 0.013 \\
5 & 34.723 & 5.361 & 9.475 & 0.001 & 0.000 \\
6 & 40.672 & 7.979 & 13.228 & 9.560 & 2.416 \\
7 & 43.444 & 11.154 & 17.390 & 11.384 & 3.155 \\
8 & 44.680 & 15.276 & 21.803 & 17.935 & 2.048 \\
9 & $45.476^{*}$ & 20.224 & 25.914 & 14.364 & 1.505 \\
10 & $46.165^{*}$ & 25.215 & 29.133 & 15.547 & 0.899 \\
15 & $45.657^{*}$ & 35.789 & 29.934 & $48.036^{*}$ & 1.440 \\
\hline
\end{tabular}

Notes: Cf. Table 7. 
Table 9: Test results for bond returns with 1 month holding period

(a) Japan

\begin{tabular}{llllll}
\hline & $\mathrm{K}(\mathrm{BN})$ & $\mathrm{K}(\mathrm{CCK})$ & $\mathrm{K}(\mathrm{PB})$ & $\mathrm{KQ}(\mathrm{PB})$ & $\mathrm{HQ}(\mathrm{PB})$ \\
\hline 1 & $1933.570^{*}$ & 0.489 & 7.249 & 13.941 & 1.675 \\
2 & $219.025^{*}$ & 5.411 & 11.809 & 0.500 & 0.066 \\
3 & $123.997^{*}$ & 8.317 & 14.336 & 6.713 & 0.580 \\
4 & $113.341^{*}$ & 13.424 & 18.900 & 8.556 & 0.993 \\
5 & $132.395^{*}$ & 15.756 & 20.440 & 0.244 & 0.015 \\
6 & $170.780^{*}$ & 14.588 & 19.889 & 7.782 & 0.235 \\
7 & $223.301^{*}$ & 11.998 & 18.530 & 9.304 & 1.451 \\
8 & $282.928^{*}$ & 9.562 & 17.093 & 6.773 & 1.185 \\
9 & $340.382^{*}$ & 7.720 & 15.864 & 2.401 & 0.434 \\
10 & $387.724^{*}$ & 6.414 & 14.891 & 0.795 & 0.066 \\
15 & $452.542^{*}$ & 3.701 & 12.335 & 6.844 & 0.453 \\
\hline
\end{tabular}

(b) US

\begin{tabular}{llllll}
\hline & $\mathrm{K}(\mathrm{BN})$ & $\mathrm{K}(\mathrm{CCK})$ & $\mathrm{K}(\mathrm{PB})$ & $\mathrm{KQ}(\mathrm{PB})$ & $\mathrm{HQ}(\mathrm{PB})$ \\
\hline 1 & $64.752^{*}$ & $80.387^{*}$ & $82.572^{*}$ & 5.108 & 0.453 \\
2 & 14.855 & 28.601 & 24.892 & 5.607 & 0.878 \\
3 & 0.912 & 6.765 & 3.846 & 22.723 & 2.335 \\
4 & 1.158 & 2.543 & 0.436 & 16.180 & 1.371 \\
5 & 7.064 & 1.119 & 0.022 & 11.283 & 0.757 \\
6 & 13.771 & 0.161 & 0.702 & 1.812 & 0.118 \\
7 & 18.944 & 0.073 & 2.070 & 2.911 & 1.062 \\
8 & 23.385 & 0.795 & 4.061 & 1.473 & 0.406 \\
9 & 27.978 & 2.298 & 6.961 & 0.004 & 0.001 \\
10 & 32.831 & 4.749 & 11.092 & 0.026 & 0.005 \\
15 & 44.960 & 17.070 & 33.702 & 7.020 & 1.004 \\
\hline
\end{tabular}

(c) UK

\begin{tabular}{llllll}
\hline & $\mathrm{K}(\mathrm{BN})$ & $\mathrm{K}(\mathrm{CCK})$ & $\mathrm{K}(\mathrm{PB})$ & $\mathrm{KQ}(\mathrm{PB})$ & $\mathrm{HQ}(\mathrm{PB})$ \\
\hline 1 & 6.671 & 0.940 & 1.486 & 4.088 & 0.901 \\
2 & 32.650 & 6.842 & 10.358 & 11.846 & 1.218 \\
3 & $50.272^{*}$ & 13.038 & 19.168 & 12.023 & 2.509 \\
4 & $48.048^{*}$ & 22.559 & 28.431 & 24.588 & $5.061^{*}$ \\
5 & 37.298 & 33.330 & 34.437 & 20.334 & 2.733 \\
6 & 24.975 & 38.386 & 32.990 & $109.702^{*}$ & $5.618^{*}$ \\
7 & 14.806 & 37.183 & 27.712 & 11.207 & 1.891 \\
8 & 7.735 & 32.027 & 22.119 & 1.286 & 0.236 \\
9 & 3.328 & 24.040 & 16.941 & 0.013 & 0.002 \\
10 & 0.930 & 16.018 & 12.341 & 4.266 & 0.124 \\
15 & 7.133 & 2.185 & 0.593 & 0.110 & 0.049 \\
\hline
\end{tabular}


Table 9: (Continued) Test results for bond returns with 1 month holding period

(d) Canada

\begin{tabular}{llllll}
\hline & $\mathrm{K}(\mathrm{BN})$ & $\mathrm{K}(\mathrm{CCK})$ & $\mathrm{K}(\mathrm{PB})$ & $\mathrm{KQ}(\mathrm{PB})$ & $\mathrm{HQ}(\mathrm{PB})$ \\
\hline 1 & 23.741 & 35.256 & 34.806 & 13.855 & 1.445 \\
2 & 12.786 & 31.887 & 26.644 & 21.486 & 1.956 \\
3 & 7.823 & 22.191 & 16.516 & 32.777 & $6.519^{*}$ \\
4 & 5.070 & 11.131 & 8.009 & $63.810^{*}$ & $7.429^{*}$ \\
5 & 3.529 & 4.108 & 3.086 & 17.011 & 2.428 \\
6 & 2.745 & 0.648 & 0.756 & 15.029 & 2.728 \\
7 & 2.515 & 0.014 & 0.050 & 4.612 & 0.609 \\
8 & 2.732 & 0.398 & 0.023 & 3.182 & 0.732 \\
9 & 3.320 & 0.711 & 0.102 & 1.267 & 0.291 \\
10 & 4.162 & 0.772 & 0.122 & 0.643 & 0.151 \\
15 & 9.124 & 1.465 & 0.075 & 0.299 & 0.041 \\
\hline
\end{tabular}

(e) Germany

\begin{tabular}{llllll}
\hline & $\mathrm{K}(\mathrm{BN})$ & $\mathrm{K}(\mathrm{CCK})$ & $\mathrm{K}(\mathrm{PB})$ & $\mathrm{KQ}(\mathrm{PB})$ & $\mathrm{HQ}(\mathrm{PB})$ \\
\hline 1 & 0.484 & 8.144 & 3.147 & 36.328 & 4.279 \\
2 & 0.043 & 1.059 & 0.559 & 9.662 & 1.032 \\
3 & 0.193 & 0.011 & 0.021 & 13.579 & 0.770 \\
4 & 0.857 & 1.753 & 1.147 & 10.373 & 0.512 \\
5 & 1.822 & 9.125 & 4.994 & $82.009^{*}$ & $4.706^{*}$ \\
6 & 3.073 & 27.701 & 13.529 & $259.559^{*}$ & $13.625^{*}$ \\
7 & 4.412 & $57.677^{*}$ & 26.825 & 83.484 & $9.568^{*}$ \\
8 & 5.405 & $82.420^{*}$ & 38.920 & 52.018 & $9.888^{*}$ \\
9 & 5.619 & $87.427^{*}$ & 42.089 & 62.292 & $9.890^{*}$ \\
10 & 4.965 & $75.511^{*}$ & 36.410 & 48.764 & $8.855^{*}$ \\
15 & 0.188 & 7.519 & 3.951 & 0.040 & 0.002 \\
\hline
\end{tabular}

Notes: Cf. Table 7. 
Table 10: Descriptive statistics for exchange rates

(a) Daily Data

\begin{tabular}{rrrrrrrrr}
\hline & Med. & Mean & S.D. & Skew. & Kurt. & AC(1) & Bowley & Pearson \\
\hline AUD & 0.000 & 0.000 & 0.006 & -0.315 & 6.770 & -0.025 & -0.012 & -0.032 \\
CAD & 0.000 & 0.000 & 0.003 & 0.007 & 5.294 & -0.034 & 0.004 & 0.009 \\
JPY & 0.000 & 0.000 & 0.007 & 0.486 & 8.185 & 0.013 & -0.006 & 0.014 \\
NZD & 0.000 & 0.000 & 0.007 & -0.222 & 6.803 & -0.006 & 0.021 & 0.001 \\
CHF & 0.000 & 0.000 & 0.007 & 0.069 & 4.557 & -0.017 & 0.020 & 0.013 \\
GBP & 0.000 & 0.000 & 0.006 & -0.168 & 5.652 & 0.011 & 0.027 & 0.009 \\
\hline
\end{tabular}

(b) Weekly Data.

\begin{tabular}{rrrrrrrrr}
\hline & Med. & Mean & S.D. & Skew. & Kurt. & $\mathrm{AC}(1)$ & Bowley & Pearson \\
\hline AUD & 0.001 & 0.000 & 0.013 & -0.717 & 5.037 & -0.001 & -0.042 & -0.087 \\
CAD & 0.000 & 0.000 & 0.008 & 0.012 & 4.136 & -0.032 & -0.092 & -0.037 \\
JPY & -0.001 & 0.000 & 0.016 & 1.027 & 10.613 & -0.021 & 0.041 & 0.071 \\
NZD & 0.001 & 0.000 & 0.014 & -0.699 & 5.808 & -0.023 & -0.056 & -0.080 \\
CHF & 0.000 & 0.000 & 0.016 & 0.090 & 3.655 & -0.033 & 0.014 & 0.019 \\
GBP & 0.001 & 0.000 & 0.013 & -0.486 & 6.477 & 0.020 & -0.074 & -0.051 \\
\hline
\end{tabular}

(c) Monthly Data.

\begin{tabular}{rrrrrrrrr}
\hline & Med. & Mean & S.D. & Skew. & Kurt. & AC(1) & Bowley & Pearson \\
\hline AUD & 0.002 & 0.001 & 0.029 & -0.466 & 3.611 & 0.039 & -0.041 & -0.050 \\
CAD & 0.001 & 0.001 & 0.016 & -0.147 & 3.451 & 0.026 & -0.031 & -0.027 \\
JPY & -0.000 & 0.002 & 0.034 & 0.542 & 4.771 & 0.007 & 0.055 & 0.072 \\
NZD & 0.003 & 0.001 & 0.029 & -0.278 & 3.904 & 0.051 & 0.009 & -0.041 \\
CHF & 0.001 & 0.002 & 0.033 & -0.048 & 2.900 & 0.081 & 0.019 & 0.031 \\
GBP & 0.000 & 0.001 & 0.029 & -0.692 & 5.227 & 0.066 & 0.131 & 0.036 \\
\hline
\end{tabular}

(d) Quarterly Data.

\begin{tabular}{rrrrrrrrr}
\hline & Med. & Mean & S.D. & Skew. & Kurt. & $\mathrm{AC}(1)$. & Bowley & Pearson \\
\hline AUD & 0.007 & 0.001 & 0.050 & -0.326 & 2.748 & -0.004 & -0.151 & -0.107 \\
CAD & -0.001 & 0.002 & 0.028 & 0.511 & 3.415 & 0.033 & 0.193 & 0.097 \\
JPY & -0.007 & 0.005 & 0.063 & 0.497 & 3.709 & 0.004 & 0.245 & 0.192 \\
NZD & 0.007 & 0.003 & 0.051 & -0.282 & 3.019 & 0.109 & -0.004 & -0.076 \\
CHF & 0.000 & 0.006 & 0.064 & 0.094 & 3.196 & -0.049 & 0.180 & 0.083 \\
GBP & 0.003 & 0.003 & 0.050 & -0.237 & 4.106 & 0.004 & 0.178 & 0.006 \\
\hline
\end{tabular}

Notes: Column 1 shows the currencies. Columns 2-9 report: the sample median, sample mean, sample standard deviation, sample skewness, sample kurtosis, sample autocorrelation of order 1, estimates of the Bowely coefficient of skewness and Pearson's coefficient of skewness. 
Table 11: Test results for exchange rates

(a) Daily Data

\begin{tabular}{llllll}
\hline & $\mathrm{K}(\mathrm{BN})$ & $\mathrm{K}(\mathrm{CCK})$ & $\mathrm{K}(\mathrm{PB})$ & $\mathrm{KQ}(\mathrm{PB})$ & $\mathrm{HQ}(\mathrm{PB})$ \\
\hline AUD & 3.131 & 20.156 & 14.624 & $84.767^{*}$ & $4.161^{*}$ \\
CAD & 0.013 & 0.070 & 0.007 & 9.297 & 1.922 \\
JPY & 44.506 & $81.109^{*}$ & $129.472^{*}$ & 0.043 & 0.018 \\
NZD & 6.938 & $104.365^{*}$ & $58.905^{*}$ & 5.719 & 3.783 \\
CHF & 17.212 & 18.303 & 18.354 & 2.976 & 1.534 \\
GBP & $63.148^{*}$ & 3.347 & 9.964 & 31.623 & $4.024^{*}$ \\
\hline
\end{tabular}

(b) Weekly Data

\begin{tabular}{llllll}
\hline & $\mathrm{K}(\mathrm{BN})$ & $\mathrm{K}(\mathrm{CCK})$ & $\mathrm{K}(\mathrm{PB})$ & $\mathrm{KQ}(\mathrm{PB})$ & $\mathrm{HQ}(\mathrm{PB})$ \\
\hline AUD & 16.816 & 22.683 & 22.879 & 39.901 & $6.468^{*}$ \\
CAD & 0.040 & 0.496 & 0.158 & 14.313 & $4.144^{*}$ \\
JPY & 23.765 & $169.712^{*}$ & $245.669^{*}$ & 45.165 & $5.329^{*}$ \\
NZD & 36.107 & $219.559^{*}$ & $210.016^{*}$ & 29.471 & $7.097^{*}$ \\
CHF & 10.211 & 15.042 & 18.244 & 2.178 & 0.197 \\
GBP & 42.028 & $50.985^{*}$ & 44.757 & $78.632^{*}$ & $4.083^{*}$ \\
\hline
\end{tabular}

(c) Monthly Data

\begin{tabular}{llllll}
\hline & $\mathrm{K}(\mathrm{BN})$ & $\mathrm{K}(\mathrm{CCK})$ & $\mathrm{K}(\mathrm{PB})$ & $\mathrm{KQ}(\mathrm{PB})$ & $\mathrm{HQ}(\mathrm{PB})$ \\
\hline AUD & 16.717 & 2.106 & 5.843 & 0.527 & 0.430 \\
CAD & 2.116 & 0.273 & 0.995 & 0.872 & 0.238 \\
JPY & 16.052 & 34.700 & 21.797 & 19.875 & 1.324 \\
NZD & 27.337 & 15.711 & 17.173 & 1.002 & 0.213 \\
CHF & 0.588 & 0.009 & 0.015 & 2.213 & 0.467 \\
GBP & $162.870^{*}$ & 2.858 & 17.593 & 13.412 & 1.883 \\
\hline
\end{tabular}

(d) Quarterly

\begin{tabular}{llllll}
\hline & $\mathrm{K}(\mathrm{BN})$ & $\mathrm{K}(\mathrm{CCK})$ & $\mathrm{K}(\mathrm{PB})$ & $\mathrm{KQ}(\mathrm{PB})$ & $\mathrm{HQ}(\mathrm{PB})$ \\
\hline AUD & 14.825 & 40.245 & 26.273 & 9.327 & 0.654 \\
CAD & 6.531 & 1.552 & 2.427 & 1.371 & 0.635 \\
JPY & 31.789 & 18.435 & 23.063 & 30.895 & $5.606^{*}$ \\
NZD & 37.051 & 2.817 & 7.921 & 3.733 & 0.469 \\
CHF & 1.512 & 1.262 & 1.084 & 8.808 & 0.841 \\
GBP & 31.440 & 0.051 & 2.153 & 0.897 & 0.065 \\
\hline
\end{tabular}

Notes: $\mathrm{K}(\mathrm{BN}), \mathrm{K}(\mathrm{CCK})$, and $\mathrm{K}(\mathrm{PB})$ denote $\mathrm{K}$ tests with $\phi=\phi^{B N}, \phi^{C C K}$, and $\phi^{P B}$, respectively. $\mathrm{HQ}(\mathrm{PB})$ and $\mathrm{KQ}(\mathrm{PB})$ are the modified $\mathrm{H}$ and $\mathrm{K}$ tests with $\phi^{P B}$. Significance level at $5 \%$ is 45.4 for $\mathrm{K}($.$) and \mathrm{KQ}(\mathrm{PB})$ and 3.84 for $\mathrm{HQ}(\mathrm{PB})$. The superscript $*$ indicates significance at $5 \%$ level. The number of samples for daily, weekly, monthly, and quarterly date are 5495, 1335, 307, and 83, respectively. 
Table 12: Descriptive statistics for international bond returns (JPY-USD)

(a) Daily holding period

\begin{tabular}{lllllllll}
\hline & Med. & Mean & S. D. & Skew. & Kurt. & AC(1) & Bowley & Pearson \\
\hline 1 & 0.059 & 0.006 & 2.261 & -1.029 & 12.968 & 0.010 & -0.002 & -0.023 \\
2 & 0.061 & 0.015 & 2.257 & -1.064 & 13.682 & 0.010 & 0.015 & -0.020 \\
3 & 0.064 & 0.024 & 2.280 & -1.081 & 14.117 & 0.011 & 0.022 & -0.017 \\
4 & 0.058 & 0.032 & 2.324 & -1.084 & 14.253 & 0.014 & 0.018 & -0.011 \\
5 & 0.070 & 0.039 & 2.385 & -1.078 & 14.138 & 0.018 & 0.019 & -0.013 \\
6 & 0.077 & 0.044 & 2.459 & -1.067 & 13.841 & 0.023 & 0.045 & -0.013 \\
7 & 0.078 & 0.050 & 2.544 & -1.054 & 13.427 & 0.026 & 0.043 & -0.011 \\
8 & 0.080 & 0.054 & 2.637 & -1.039 & 12.947 & 0.030 & 0.041 & -0.010 \\
9 & 0.077 & 0.059 & 2.737 & -1.022 & 12.435 & 0.032 & 0.060 & -0.007 \\
10 & 0.086 & 0.063 & 2.842 & -1.004 & 11.914 & 0.035 & 0.070 & -0.008 \\
15 & 0.133 & 0.083 & 3.402 & -0.883 & 9.609 & 0.041 & 0.038 & -0.015 \\
\hline
\end{tabular}

(b) Weekly holding period

\begin{tabular}{lllllllll}
\hline & Med. & Mean & S. D. & Skew. & Kurt. & AC(1) & Bowley & Pearson \\
\hline 1 & 0.090 & 0.034 & 0.848 & -1.634 & 15.972 & -0.069 & -0.056 & -0.066 \\
2 & 0.095 & 0.040 & 0.847 & -1.728 & 17.236 & -0.081 & -0.056 & -0.065 \\
3 & 0.105 & 0.045 & 0.854 & -1.826 & 18.627 & -0.094 & -0.069 & -0.070 \\
4 & 0.095 & 0.050 & 0.870 & -1.912 & 19.908 & -0.106 & -0.027 & -0.052 \\
5 & 0.103 & 0.054 & 0.892 & -1.980 & 20.951 & -0.115 & -0.036 & -0.054 \\
6 & 0.089 & 0.058 & 0.920 & -2.028 & 21.683 & -0.121 & 0.002 & -0.034 \\
7 & 0.091 & 0.060 & 0.951 & -2.053 & 22.079 & -0.126 & 0.001 & -0.032 \\
8 & 0.092 & 0.063 & 0.985 & -2.056 & 22.142 & -0.128 & 0.041 & -0.029 \\
9 & 0.107 & 0.065 & 1.022 & -2.039 & 21.896 & -0.130 & 0.048 & -0.041 \\
10 & 0.106 & 0.067 & 1.060 & -2.002 & 21.382 & -0.130 & 0.048 & -0.036 \\
15 & 0.142 & 0.075 & 1.257 & -1.643 & 16.654 & -0.123 & 0.028 & -0.053 \\
\hline
\end{tabular}

(c) Monthly holding period

\begin{tabular}{lllllllll}
\hline & Med. & Mean & S. D. & Skew. & Kurt. & AC(1) & Bowley & Pearson \\
\hline 1 & 0.041 & 0.036 & 0.127 & -0.898 & 7.336 & -0.069 & -0.038 & -0.046 \\
2 & 0.046 & 0.040 & 0.124 & -0.993 & 8.045 & -0.080 & -0.011 & -0.048 \\
3 & 0.042 & 0.044 & 0.122 & -1.079 & 8.587 & -0.081 & 0.074 & 0.017 \\
4 & 0.044 & 0.048 & 0.122 & -1.134 & 8.857 & -0.076 & 0.190 & 0.031 \\
5 & 0.046 & 0.051 & 0.124 & -1.159 & 8.875 & -0.068 & 0.194 & 0.035 \\
6 & 0.050 & 0.053 & 0.127 & -1.162 & 8.721 & -0.061 & 0.137 & 0.024 \\
7 & 0.048 & 0.056 & 0.130 & -1.155 & 8.476 & -0.054 & 0.243 & 0.060 \\
8 & 0.052 & 0.058 & 0.134 & -1.144 & 8.197 & -0.048 & 0.169 & 0.044 \\
9 & 0.056 & 0.060 & 0.139 & -1.131 & 7.917 & -0.043 & 0.114 & 0.025 \\
10 & 0.059 & 0.061 & 0.144 & -1.118 & 7.651 & -0.039 & 0.080 & 0.012 \\
15 & 0.067 & 0.064 & 0.172 & -1.023 & 6.529 & -0.028 & 0.065 & -0.013 \\
\hline
\end{tabular}

Notes: Column 1 shows the maturities. Columns 2-9 report the sample median, sample standard deviation, sample skewness, sample kurtosis, sample autocorrelation of order 1, estimates of Bowley and Pearson coefficients, respectively. 
Table 13: Test results for international bond returns (JPY-USD)

(a) Daily holding period

\begin{tabular}{llllll}
\hline & $\mathrm{K}(\mathrm{BN})$ & $\mathrm{K}(\mathrm{CCK})$ & $\mathrm{K}(\mathrm{PB})$ & $\mathrm{KQ}(\mathrm{PB})$ & $\mathrm{HQ}(\mathrm{PB})$ \\
\hline 1 & $193.744^{*}$ & 19.433 & 33.857 & 2.972 & 0.240 \\
2 & $282.612^{*}$ & 19.005 & 32.628 & 0.376 & 0.031 \\
3 & $380.548^{*}$ & 15.203 & 28.345 & 0.047 & 0.004 \\
4 & $469.259^{*}$ & 13.848 & 26.460 & 4.971 & 0.474 \\
5 & $535.509^{*}$ & 14.348 & 27.055 & 3.019 & 0.224 \\
6 & $574.485^{*}$ & 15.499 & 29.278 & 4.266 & 0.257 \\
7 & $588.538^{*}$ & 17.511 & 32.901 & 11.538 & 0.617 \\
8 & $582.340^{*}$ & 20.459 & 37.718 & 22.421 & 1.049 \\
9 & $560.693^{*}$ & 23.971 & 43.287 & 31.619 & 1.974 \\
10 & $528.407^{*}$ & 27.770 & $49.148^{*}$ & $61.132^{*}$ & 1.834 \\
15 & $342.833^{*}$ & 43.809 & $71.360^{*}$ & 10.673 & 0.661 \\
\hline
\end{tabular}

(b) Weekly holding period

\begin{tabular}{llllll}
\hline & $\mathrm{K}(\mathrm{BN})$ & $\mathrm{K}(\mathrm{CCK})$ & $\mathrm{K}(\mathrm{PB})$ & $\mathrm{KQ}(\mathrm{PB})$ & $\mathrm{HQ}(\mathrm{PB})$ \\
\hline 1 & $314.772^{*}$ & $50.179^{*}$ & $67.859^{*}$ & 3.724 & 1.609 \\
2 & $441.522^{*}$ & $49.710^{*}$ & $63.500^{*}$ & 11.510 & 2.167 \\
3 & $569.383^{*}$ & 38.198 & $49.561^{*}$ & 26.746 & 3.223 \\
4 & $662.870^{*}$ & 26.277 & 36.629 & 5.144 & 0.915 \\
5 & $717.541^{*}$ & 18.966 & 28.206 & 6.205 & 1.386 \\
6 & $742.165^{*}$ & 15.063 & 23.361 & 0.349 & 0.063 \\
7 & $744.485^{*}$ & 13.208 & 20.900 & 0.401 & 0.050 \\
8 & $727.310^{*}$ & 12.771 & 20.082 & 0.160 & 0.008 \\
9 & $691.298^{*}$ & 13.454 & 20.463 & 2.669 & 0.437 \\
10 & $638.689^{*}$ & 15.019 & 21.718 & 2.352 & 0.140 \\
15 & $330.151^{*}$ & 27.013 & 33.342 & 15.495 & 0.913 \\
\hline
\end{tabular}


Table 12: (Continued) Test results for international bond returns (JPY-USD)

(c) Monthly holding period

\begin{tabular}{llllll}
\hline & $\mathrm{K}(\mathrm{BN})$ & $\mathrm{K}(\mathrm{CCK})$ & $\mathrm{K}(\mathrm{PB})$ & $\mathrm{KQ}(\mathrm{PB})$ & $\mathrm{HQ}(\mathrm{PB})$ \\
\hline 1 & $83.211^{*}$ & 0.794 & 3.094 & 1.209 & 0.222 \\
2 & $107.897^{*}$ & 0.004 & 1.585 & 3.721 & 0.328 \\
3 & $134.629^{*}$ & 0.121 & 1.047 & 2.839 & 0.462 \\
4 & $148.633^{*}$ & 0.182 & 0.969 & 5.964 & 1.276 \\
5 & $150.171^{*}$ & 0.106 & 1.134 & 14.409 & 1.564 \\
6 & $145.765^{*}$ & 0.024 & 1.458 & 9.317 & 0.782 \\
7 & $141.102^{*}$ & 0.000 & 1.899 & 25.690 & 2.637 \\
8 & $139.121^{*}$ & 0.028 & 2.435 & 24.301 & 1.707 \\
9 & $140.815^{*}$ & 0.090 & 3.063 & 13.183 & 0.820 \\
10 & $146.250^{*}$ & 0.182 & 3.803 & 3.075 & 0.369 \\
15 & $212.666^{*}$ & 2.166 & 11.651 & 1.778 & 0.122 \\
\hline
\end{tabular}

Notes: $\mathrm{K}(\mathrm{BN}), \mathrm{K}(\mathrm{CCK})$, and $\mathrm{K}(\mathrm{PB})$ denote $\mathrm{K}$ tests with $\phi=\phi^{B N}, \phi^{C C K}$, and $\phi^{P B}$, respectively. $\mathrm{HQ}(\mathrm{PB})$ and $\mathrm{KQ}(\mathrm{PB})$ are the modified $\mathrm{H}$ and $\mathrm{K}$ tests with $\phi^{P B}$. Significance level at 5\% is 45.4 for $\mathrm{K}($.$) and \mathrm{KQ}(\mathrm{PB})$ and 3.84 for $\mathrm{HQ}(\mathrm{PB})$. The superscript $*$ indicates significance at $5 \%$ level. The number of observations for daily, weekly and monthly are 2563, 543 and 125 . 
Figure 1: Comparison of the scale of different asymmetry measures

(a)
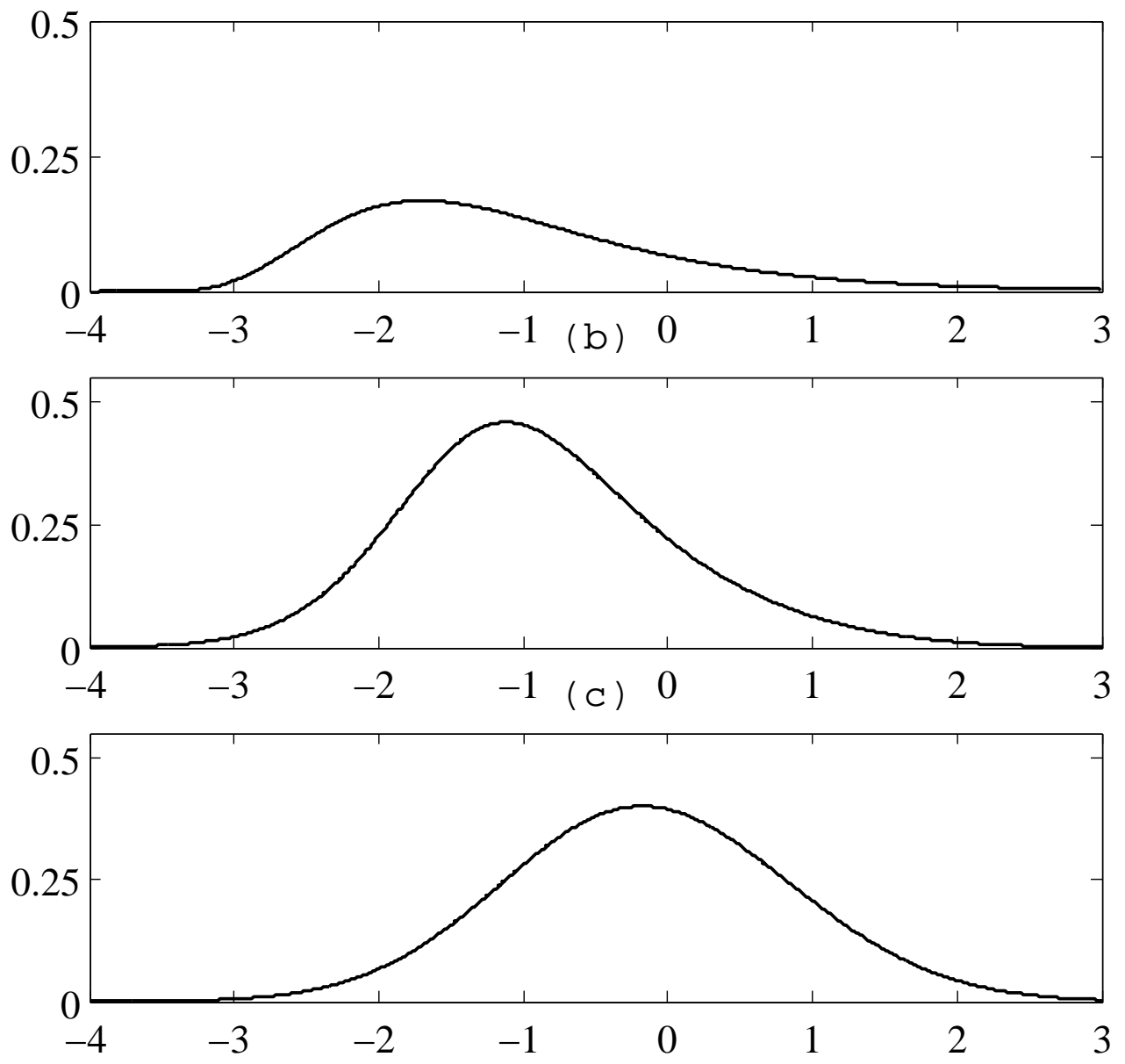

Notes: For the distribution in (a), the values of the coefficient of skewness, the Bowley coefficient and the Pearson coefficient are 1.32, 0.13, and 0.18. For the distribution in (b), the corresponding figures are 0.437, 0.068, and 0.083. For the distribution in (c), the corresponding figures are $0.063,0.012$, and 0.014 . 
Figure 2: Coefficient of skewness of ex-post government bond returns for 1 to 15 years to maturity.
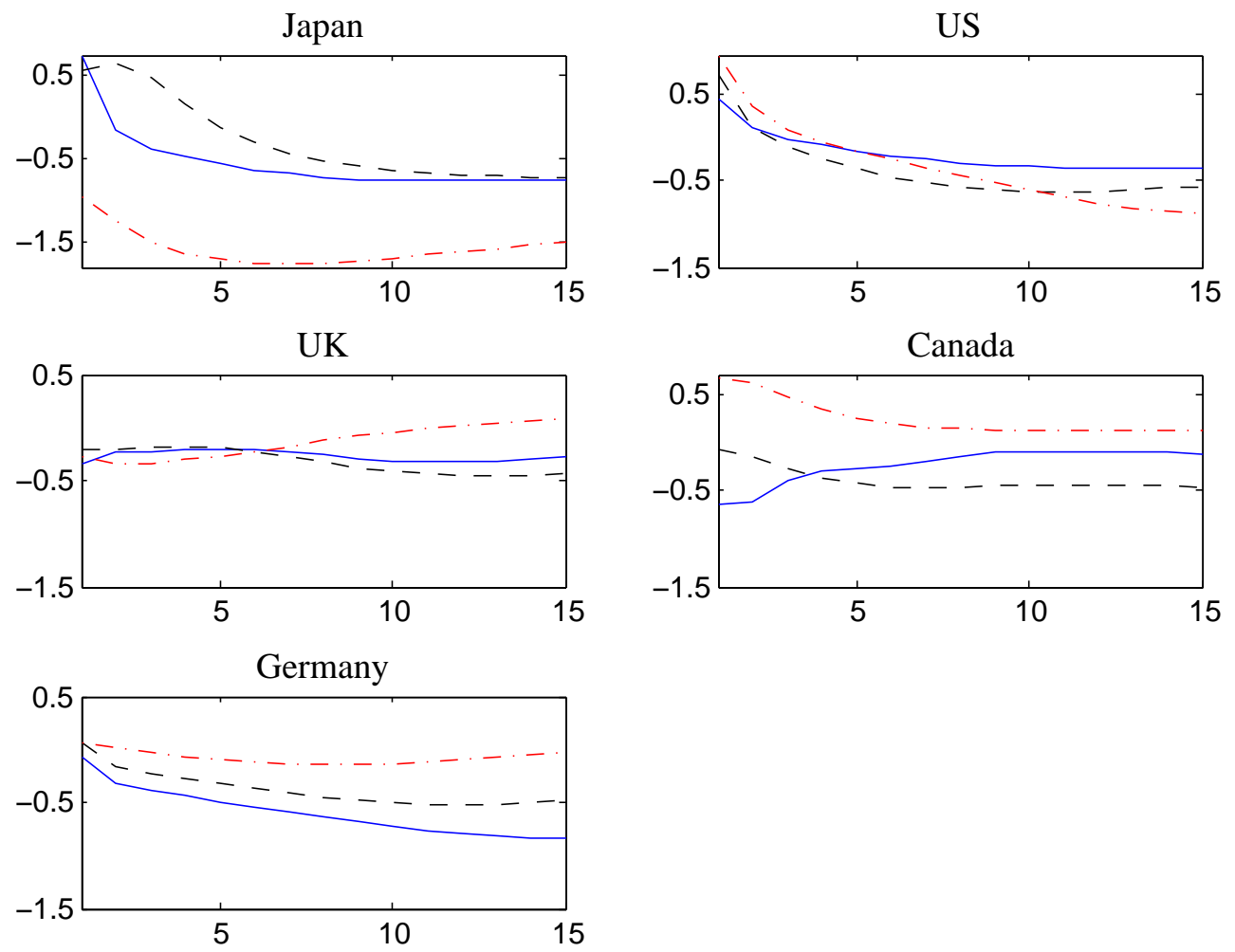

Notes: - are daily holding periods, - - are weekly holding periods and $-\cdot-$ are monthly holding periods. 
Figure 3: The Bowley coefficient of ex-post government bond returns for 1 to 15 years to maturity.
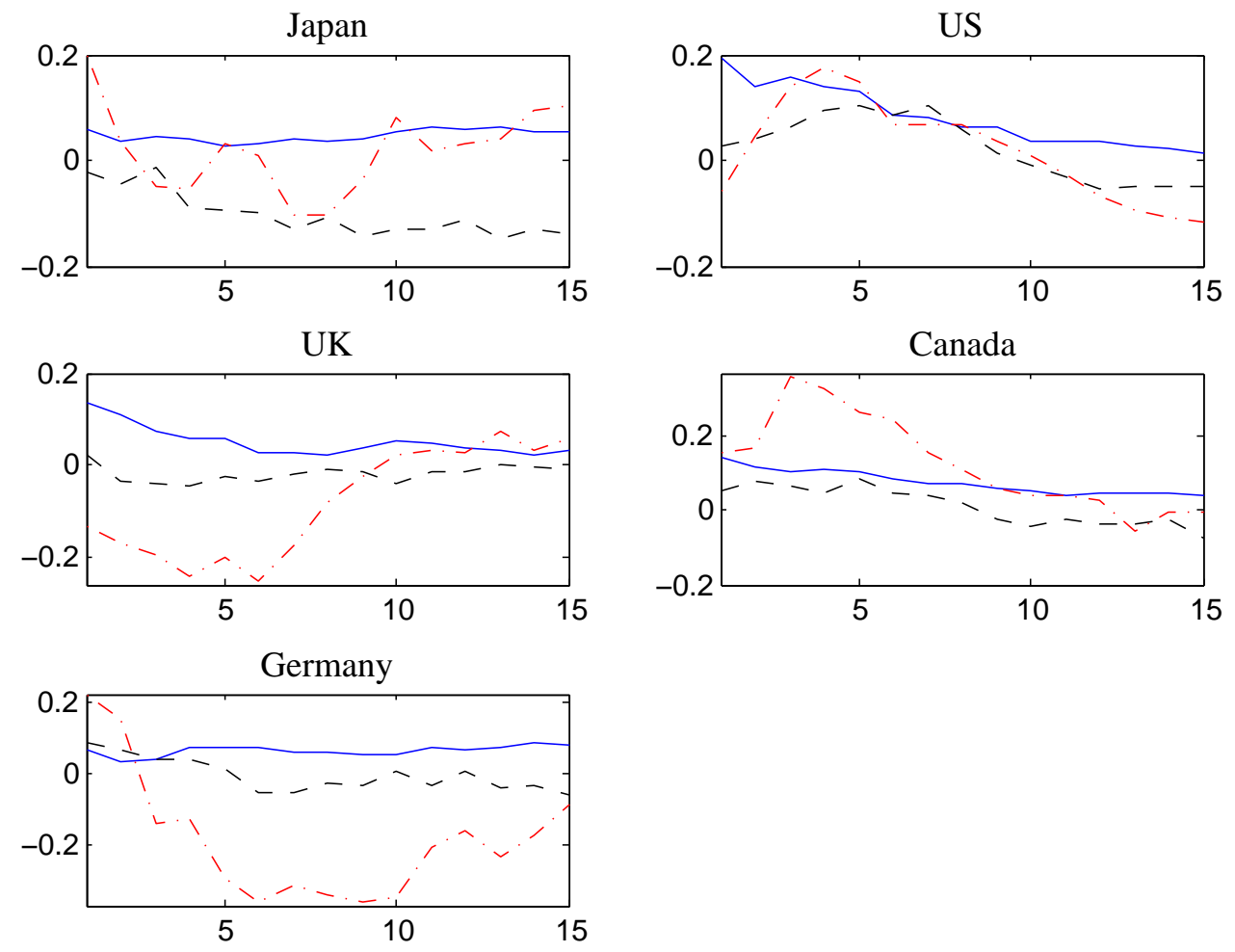

Notes: - are daily holding periods, - - are weekly holding periods and $-\cdot-$ are monthly holding periods. 
Figure 4: The Pearson coefficient of ex-post government bond returns for 1 to 15 years to maturity.
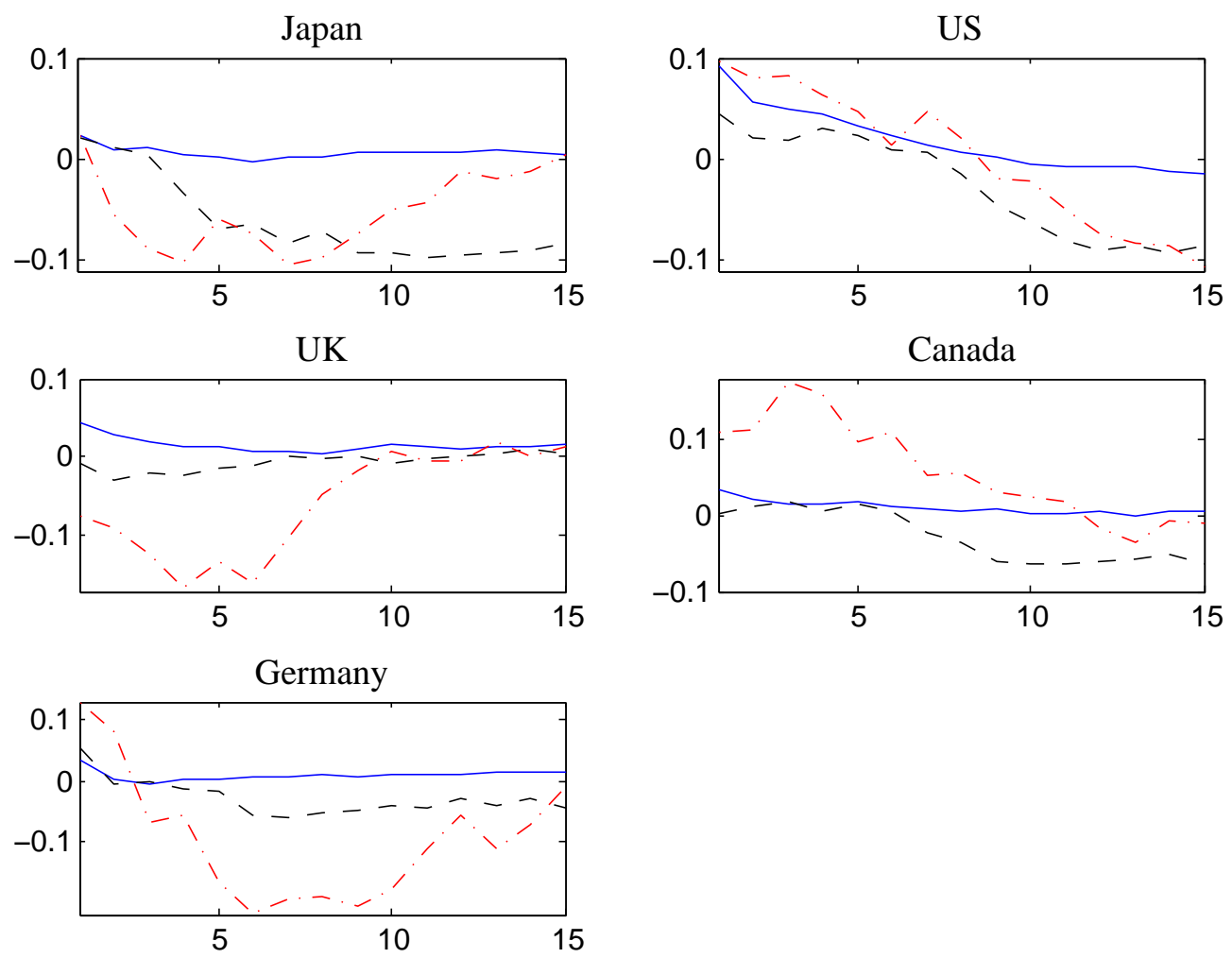

Notes: - are daily holding periods, - - are weekly holding periods and - - - are monthly holding periods. 
Figure 5: Outliers in 1 year Japanese government bond returns
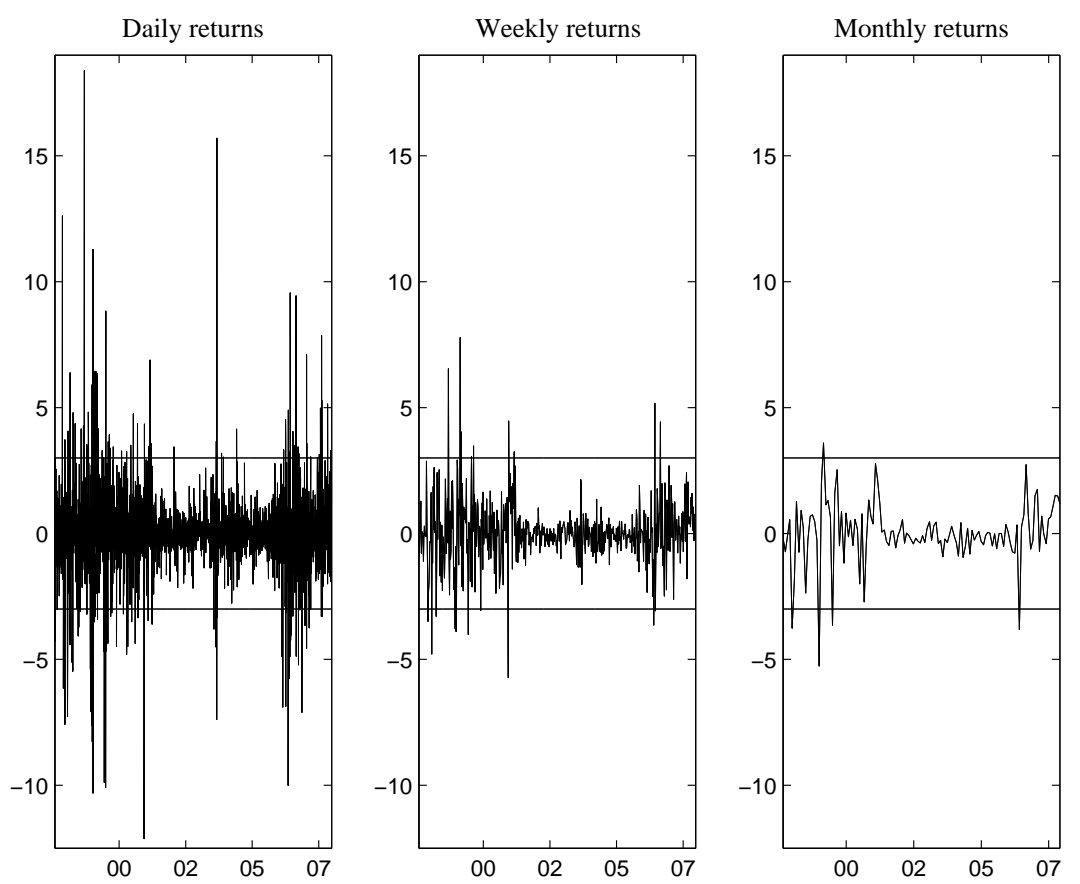

Note: The figure shows the time series of government bond returns standardized by median and interquartile range. For normally distributed variables, the probability that a realization standardized by median and interquartile range exceeds 3 in absolute value is about 0.00005 . 
Figure 6: Outliers in 10 year Japanese government bond returns
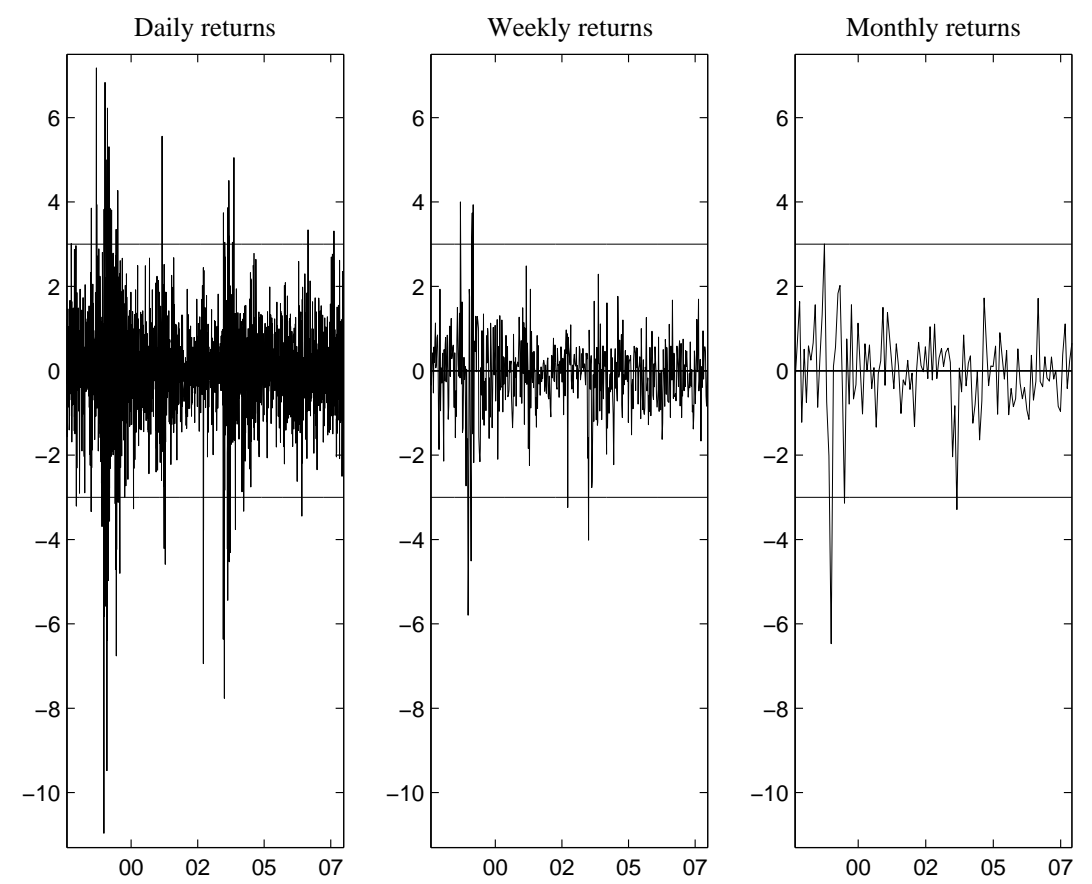

Note: Cf. Figure 5. 
Figure 7: Kernel density estimates of Japanese 10 year bond excess returns.
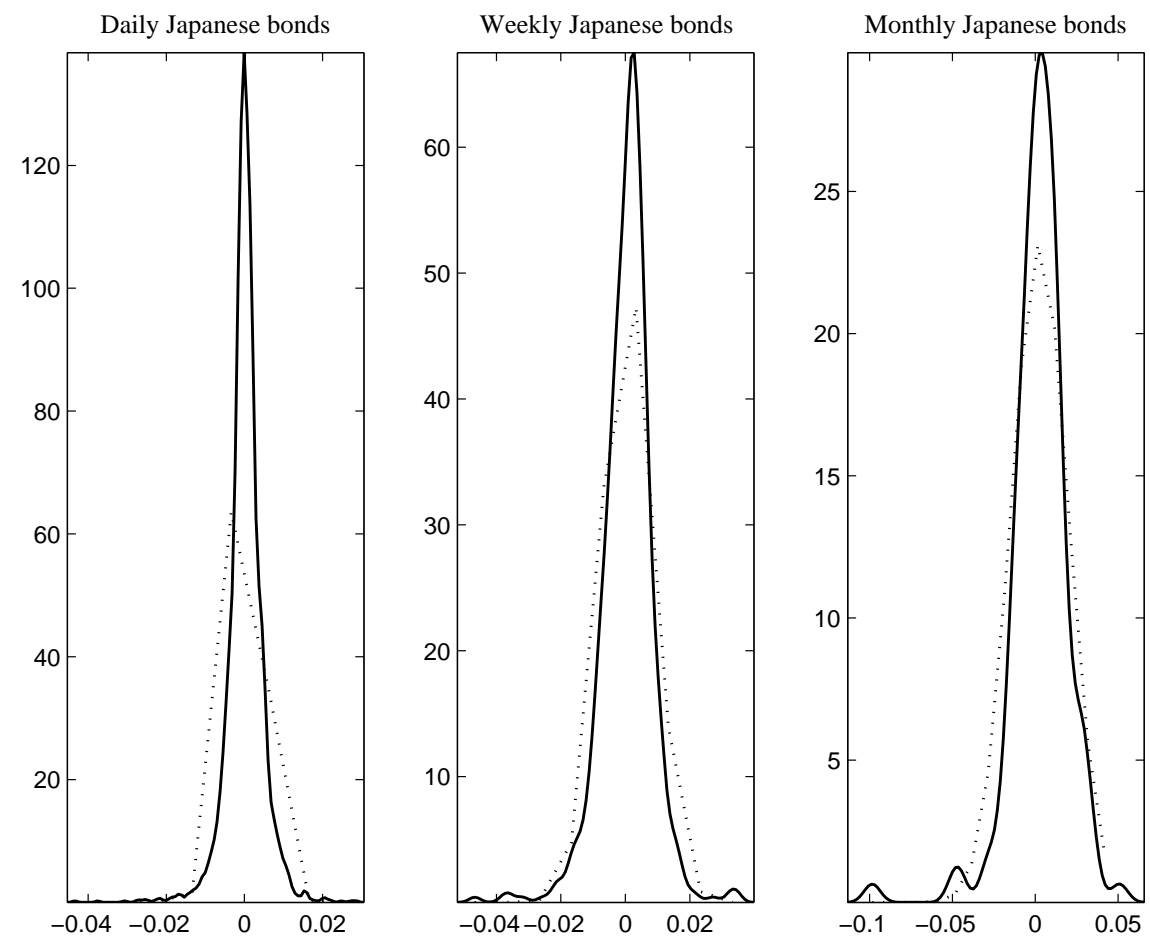

Notes: A normal distribution with equal mean and standard deviation is superimposed on the estimated kernel densities. 
Figure 8: Outliers in JPY exchange rates
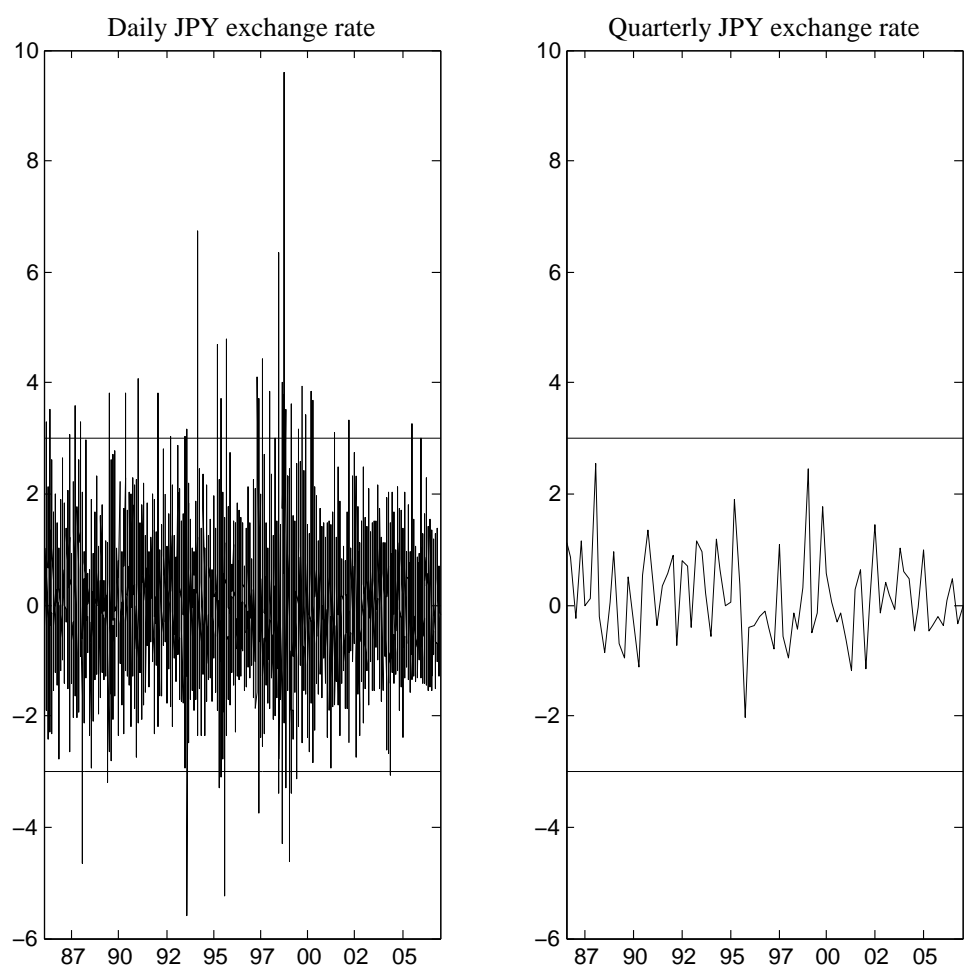

Note: Cf. Figure 5. 
Figure 9: Kernel density estimates of Japanese exchange rates.
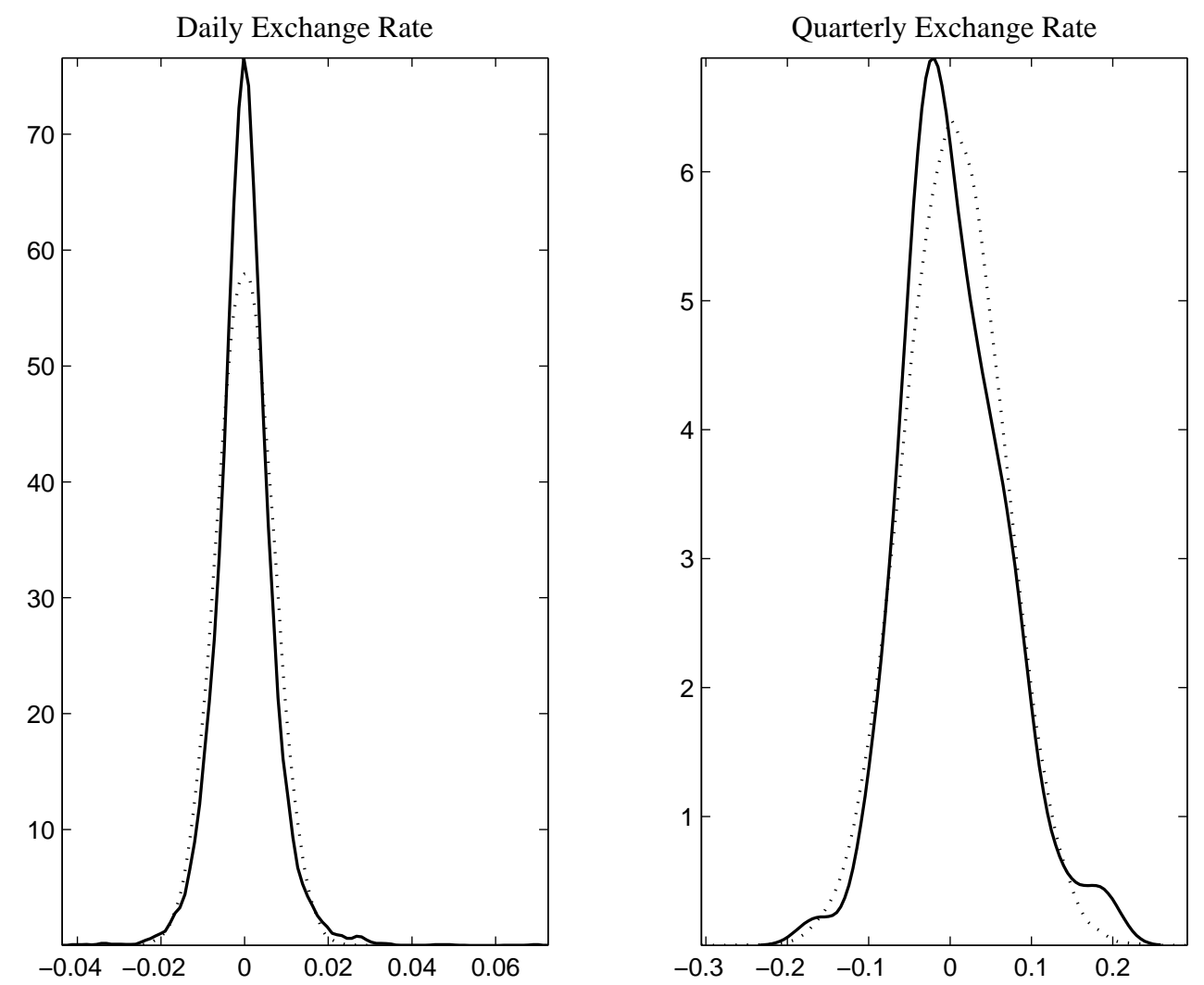

Notes: A normal distribution with equal mean and standard deviation is superimposed on the estimated kernel densities. 
Figure 10: Asymmetry measures of international government bond returns for 1 to 15 years to maturity.
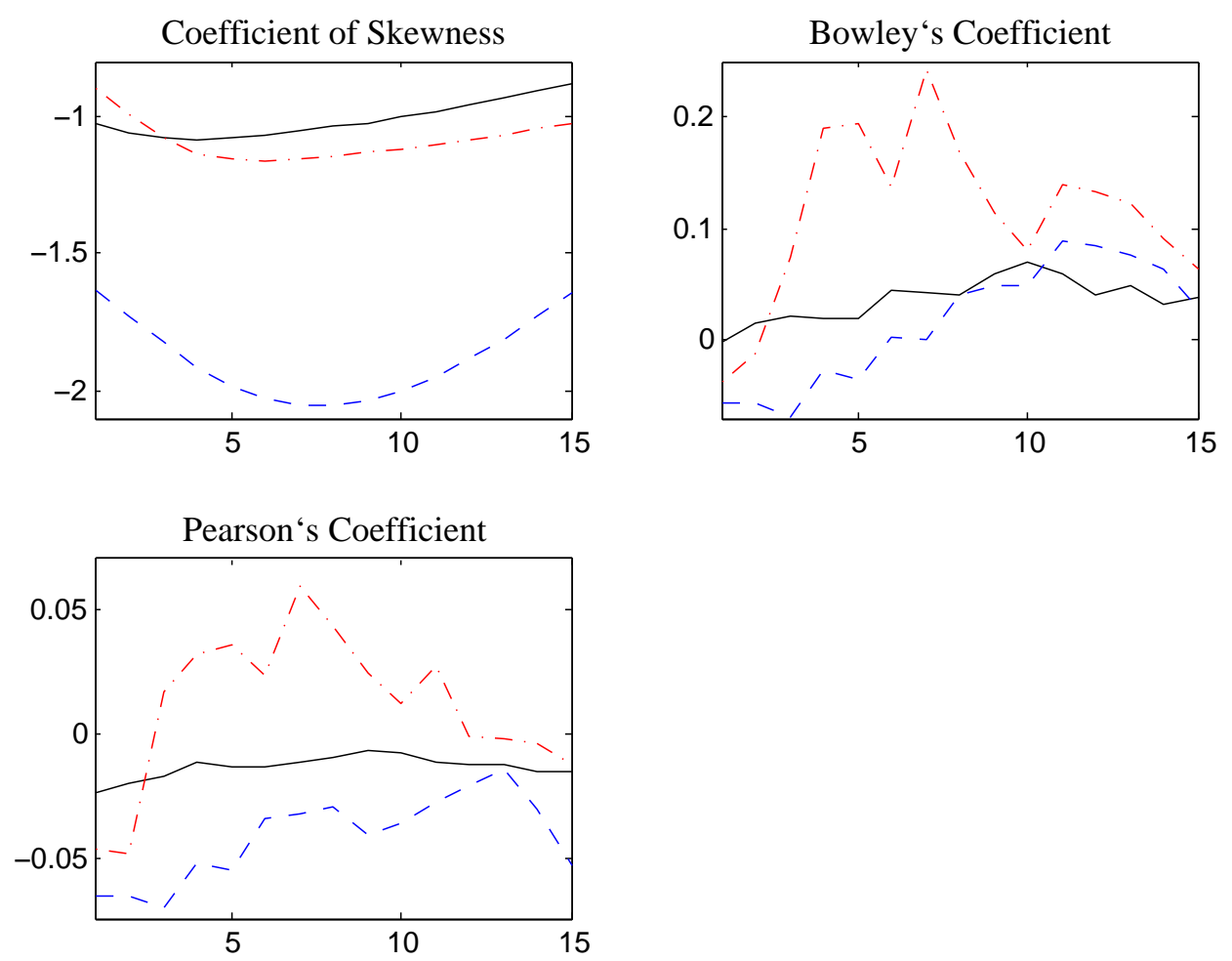

Notes: - are daily holding periods, - - are weekly holding periods and - - - are monthly holding periods. An international bond trade is an investment where a one year Japanese bond is invested in a long US bond 
Figure 11: Outliers in 1 year international government bond returns where a one year Japanese bond is invested in a long US bond
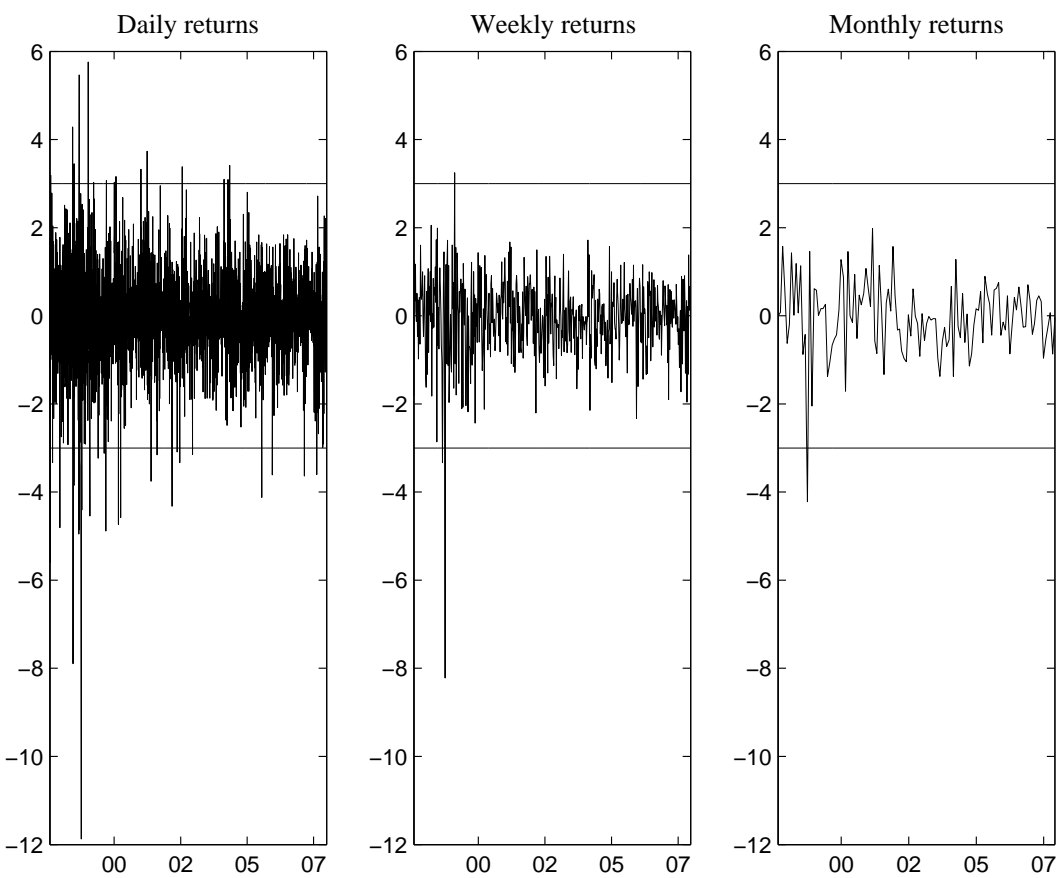

Note: Cf. Figure 5. 
Figure 12: Outliers in 10 tear international government bond returns where a one year Japanese bond is invested in a long US bond
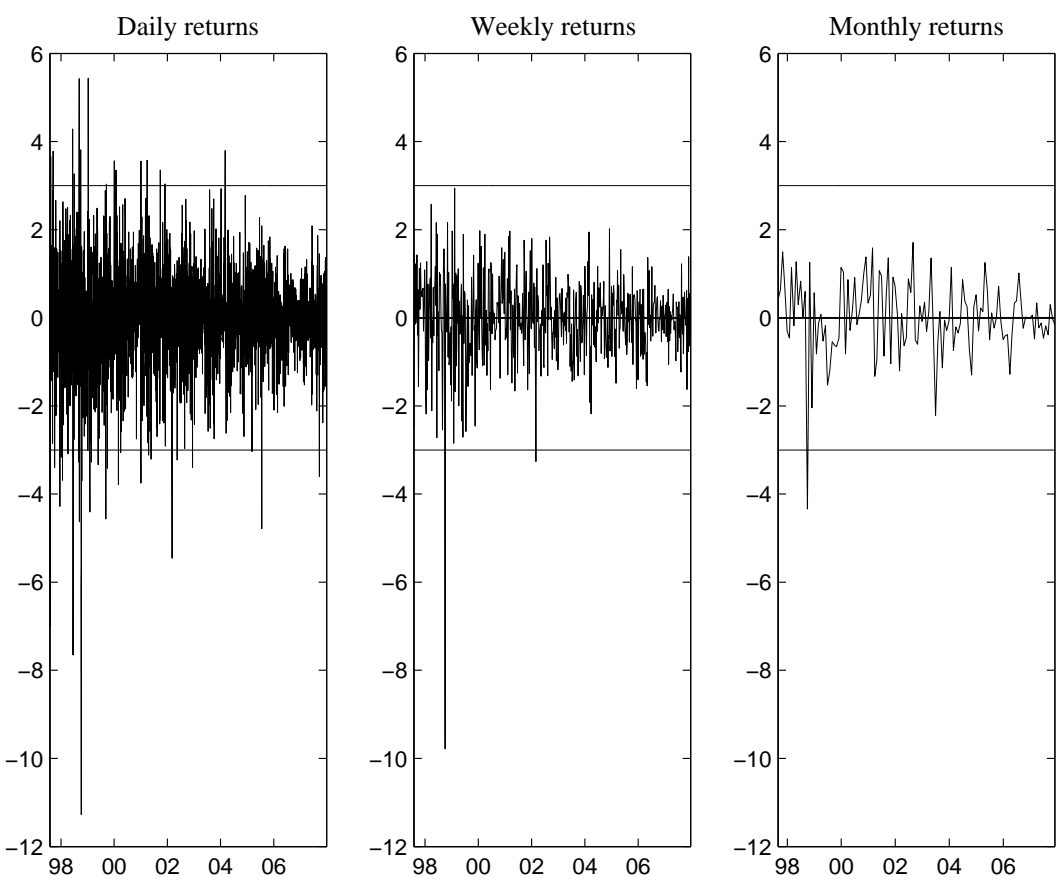

Note: Cf. Figure 5. 
Figure 13: Kernel density estimates of international 10 year government bond excess returns where a one year Japanese bond is invested in a long US bond.
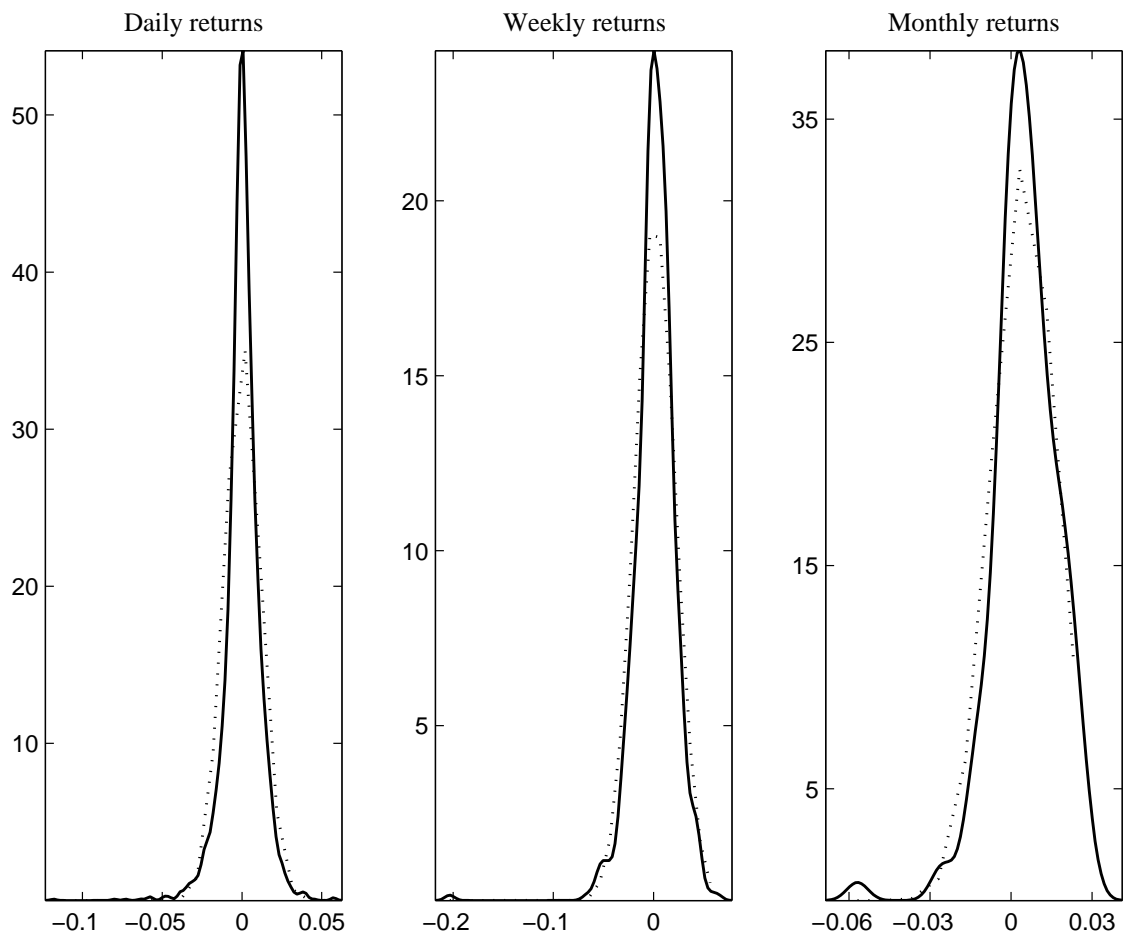

Notes: A normal distribution with equal mean and standard deviation is superimposed on the estimated kernel densities. 